\title{
INFERENTIAL MEASUREMENT OF SAG MILL PARAMETERS IV: INFERENTIAL MODEL VALIDATION
}

\author{
T. A. APELT A $^{* \S}$ and N. F. THORNHILL ${ }^{\S}$ \\ ${ }^{\S}$ Centre for Process Systems Engineering, Imperial College SW7 2BY. Email: thomasapelt@yahoo.com \\ * Department of Chemical Engineering, University of Sydney NSW 2006 \\ (Received ; accepted )
}

\begin{abstract}
This paper discusses a case study application of inferential measurement models for semiautogenous grinding (SAG) mills and is the fourth paper in a series of five papers on Inferential Measurement of SAG Mill Parameters. The development of the inferential measurement models of SAG mill discharge and feed streams and mill rock and ball charge levels, detailed earlier in the series, is summarised. The models are then tested on plant data for validation and analysis. Model characteristics are explored to highlight model sensitivity and relative uncertainty. The results are encouraging while limitations are noted and potential avenues for further research are discussed.
\end{abstract}

\section{Keywords}

SAG milling; Mineral processing; Modelling; Simulation; Process control

\section{INTRODUCTION}

This paper describes a case study application of inferential models of the mill inventory and various streams in the primary grinding circuit and is a continuation of earlier work (Apelt et al., 2001a, Apelt et al., 2002a, Apelt et al., 2002b). The models presented below in Step 3 of the Inferential Measurement Model Summary Section recapitulate models presented in the initial paper (Apelt et al., 2001a). The models presented below in Steps 1 to 2 and 4 to 6 recapitulate models presented in the third paper (Apelt et $a l ., 2002 b$ ). This paper is based on the research and findings presented in a University of Sydney PhD thesis dissertation (Apelt, 2007).

A brief circuit description is followed by a summary of the inferential measurement models and their calculation sequence. The Results and Discussion first looks at model validation on plant data and model limitations. The model characteristics are then discussed further, including sensitivity analysis, calculation sequence, charge estimate contours and relative uncertainty of the charge estimates. Model limitations and features to be aware of are noted in the model validation process.

\section{CIRCUIT DESCRIPTION}

The discussion centres on the primary grinding circuit shown in Figure 1 which also shows process measurements relevant to this work. The abbreviations indicate the available process measurements for mass flowrate $(T P H)[\mathrm{t} / \mathrm{hr}]$, volumetric flowrate $(C M P H)\left[\mathrm{m}^{3} / \mathrm{hr}\right]$, stream density $(\%$ sols $)$ [\% solids w/w], mill powerdraw $k W[\mathrm{~kW}]$, and mill load cell weight $L C[\mathrm{t}]$. This example of a grinding circuit would be considered well insturmented according to the guidelines defined by Fuenzalida et al. (1996). The 
available measurements are as follows:

- $\quad \mathrm{SAG}$ mill fresh (stockpile) feed $[\mathrm{t} / \mathrm{hr}]$

- $\quad$ SAG mill feed water addition $\left[\mathrm{m}^{3} / \mathrm{hr}\right]$

- $\quad$ SAG mill powerdraw [kW]

- $\quad \mathrm{SAG}$ mill load cell [t]
- Cyclone feed water addition $\left[\mathrm{m}^{3} / \mathrm{hr}\right]$

- Cyclone feedrate $\left[\mathrm{m}^{3} / \mathrm{hr}\right]$

- Cyclone feed density [\% solids w/w]

- Oversize crusher feedrate [t/hr]

Ore is fed to the SAG mill for primary grinding. The mill discharge is screened with the oversized material recycling via a gyratory cone crusher, and the screen undersize being diluted with water and fed to the primary cyclones for classification. Primary cyclone underflow is split between a small recycle stream to the SAG mill feedchute and a ball mill feed stream. The primary grinding circuit products are subjected to further size reduction (ball mill), classification (cyclones) and separation (flash flotation) in the secondary grinding circuit. Further details of the grinding circuit and the other sections of the processing plant may be found elsewhere (Apelt et al., 2001a,b; Freeman et al., 2000; Apelt, 2007).

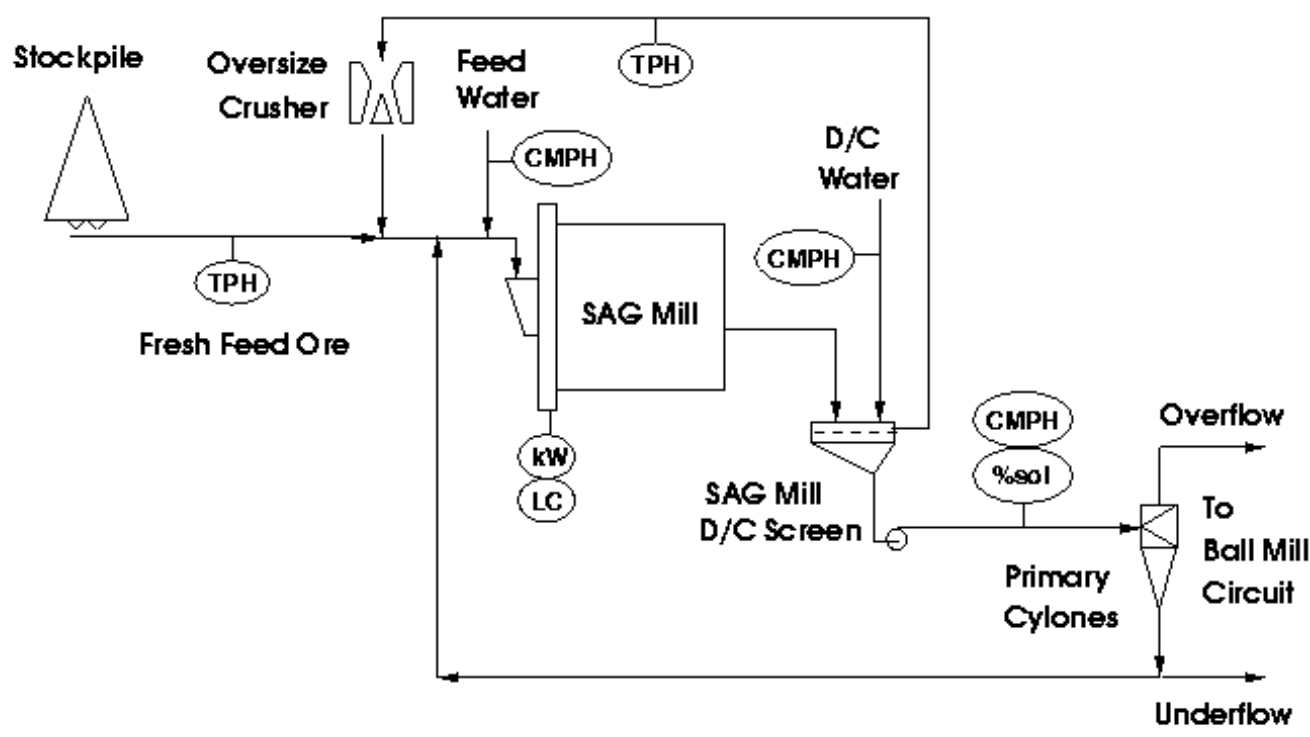

Fig.1 Primary grinding circuit process flowsheet

\section{INFERENTIAL MEASUREMENT MODEL SUMMARY}

This section recapitulates the inferential rmeasurement models relevant to this paper. Full model details are found elsewhere (Apelt et al., 2001a; Apelt et al., 2002b; Apelt, 2007).

\section{Model Overview}

The Inferential measurement models of the SAG mill inventories, feed rate and sizing and mill discharge rate and sizing requires are determined in the following six-step sequence:

1. Oversize crusher feed, primary cyclone feed, SAG mill discharge, including the transfer sizes $\left(T_{80} \ldots T_{20}\right)$;

2. SAG mill rock charge; 
3. SAG mill fractional total filling, $J_{t}$, fractional ball filling, $J_{b}$, and fractional rock charge filling, $\mathrm{Jr},\left(J_{r}=J_{t}-J_{b}\right)$;

4. SAG mill total feed;

5. Oversize crusher product and primary cyclone underflow; and,

6. SAG mill fresh feed, including the feed sizes $\left(F_{80} \ldots F_{20}\right)$.

\section{Step 1: Oversize Crusher Feed, Primary Cyclone Feed and SAG Mill Discharge}

\section{Oversize Crusher Feed, OSCF/oscf, and Primary Cyclone Feed, PCFD/pcfd}

The oversize crusher feed $(O S C F)$ and primary cyclone feed (PCFD) streams are calculated from the oversize crusher feedrate, primary cyclone feed flowrate and density data and assumptions about the size distributions (based on SAG mill grate size and discharge screen aperture size), see Equations (1) to (4).

$$
\begin{aligned}
O S C F_{t p h_{-} s} & =M V_{s c a t s} O S C F_{\% s w / w} \\
O S C F_{t p h_{-} l} & =M V_{s c a t s} \frac{\left(100-O S C F_{\% s w / w}\right)}{100} \\
P C F D_{t p h_{-} s} & =\frac{P C F D_{m 3 p h_{-} p} P C F D_{\% s w / w} S G_{l} S G_{s}}{P C F D_{\% s w / w} S G_{l}+\left(100-P C F D_{\% s w / w}\right) S G_{s}}
\end{aligned}
$$

$$
P C F D_{t p h_{-} l}=P C F D_{t p h_{-} s} \frac{\left(100-P C F D_{\% s w / w}\right)}{100}
$$

where $M V_{\text {scats }}$ is the oversize crusher total feedrate measured variable [t/hr], $O S C F_{t p h \_s}$ is the oversize crusher solids feedrate [t/hr], $O S C F_{t p h l}$ is the oversize crusher liquid feedrate [t/hr], $O S C F_{\% s w} w$ is the oversize crusher feed solids density [\%solids w/w], $P C F D_{t p h \_s}$ is the primary cyclone feed solids feedrate $[\mathrm{t} / \mathrm{hr}], P C F D_{t p h_{-} l}$ is the primary cyclone liquid feedrate $[\mathrm{t} / \mathrm{hr}], P C F \Phi_{\% s} w / w$ is the primary cyclone feed solids density [\% solids w/w], $P C F D_{m 3 p h \_p}\left(M V_{p c \_f l o w}\right)$ is the cyclone feed flowrate measured variable, $\left[\mathrm{m}^{3} / \mathrm{hr}\right]$, and $P C F D_{\% s w / w}\left(M V_{p c \_d e n s}\right)$ is the primary cyclone feed solids density measured variable, [\%solids $\left.w / w\right]$.

The oversize crusher feed size distribution, oscf, and the primary cyclone feed size distribution, $p c f d$, are estimated utilising the SAG mill grate size and discharge screen aperture sizes and the Rosin-Rammler size distribution function, which has been selected for its convenience and since it "has been found to fit many size distributions very well" (Napier-Munn et al.,1996).

\section{SAG Mill Discharge, SMDC/smdc}

The SAG mill discharge properties $(S M D C)$ and size distribution $(s m d c)$, including the transfer sizes $\left(T_{80}\right.$ $\ldots T_{20}$ ), are estimated by the addition of the estimated primary cyclone feed and oversize crusher feed streams less the SAG mill discharge water flowrate, see Equations (5) to (7) .

$$
\begin{aligned}
& S M D C_{t p h_{-} s}=\mathrm{OSCF}_{t p h_{-} s}+\mathrm{PCFD}_{t p h_{-} s} \\
& S M D C_{t p h_{-} l}=O S C F_{t p h_{-} l}+\mathrm{PCFD}_{t p h_{-} l}-M V_{D C_{-} H_{2 O} O} S G_{l}
\end{aligned}
$$


$s m d c=\frac{O S C F_{t p h_{-} s}}{S M D C_{t p h_{-} s}} o s c f+\frac{P C F D_{t p h_{-} s}}{S M D C_{t p h_{-} s}} p c f d$

where $S M D C_{t p h_{-} s}$ is the SAG mill solids discharge rate [t/hr], $S M D C_{t p h_{-} l}$ is the SAG mill liquid discharge rate $[\mathrm{t} / \mathrm{hr}$ ], $s m d c$ is the SAG mill discharge size distribution [\% retained $\mathrm{w} / \mathrm{w}], M V_{D C_{-} H 2 O}$ is the SAG mill discharge water addition rate measured variable $\left[\mathrm{m}^{3} / \mathrm{hr}\right]$ and $S G_{l}$ is the process water specific gravity $\left[\mathrm{t} / \mathrm{m}^{3}\right]$.

\section{Step 2: SAG Mill Rock Charge}

The SAG mill rock charge properties (SMRC) and size distribution ( $s m r c)$ are estimated by the reverseapplication of the SAG mill grate discharge function on the SAG mill discharge stream estimate, incorporating a size distribution assumption.

\section{Solids}

The mill rock charge mass by size, $S M R C_{i}$, is calculated using Equation (8).

$$
S M R C_{i}=\frac{S M D C_{i}}{d_{0} c_{i}}
$$

where $S M R C_{i}$ is the mass of SAG mill rock charge in size $i$ [t], $S M D C_{i}$ is the mass of the SAG mill discharge solids in size $i[\mathrm{t} / \mathrm{hr}], d_{0}$ is the maximum discharge rate $\left[\mathrm{hr}^{-1}\right]$, and $c_{i}$ forms a simplified version of the discharge grate classification function, Equation (9), as detailed by Napier-Munn et al. (1996).

$$
\begin{array}{rlrl}
c_{i} & =0 & & \text { for } x \geq x_{g} \\
c_{i}=\frac{x_{g}-x}{x_{g}-x_{m}} & & \text { for } x_{m}<x<x_{g} \\
c_{i}=1 & & \text { for } x \leq x_{m}
\end{array}
$$

where $c_{i}$ is the probability ( 0 to 1 ) for a particle of size $x$ passing through the mill discharge grate. Particles larger than the grate size, $x_{g}$, have a zero probability of passing through the discharge grate. The solids that have water-like behaviour solids (solids of size $<x_{m}$ ) will always pass through the grate on being presented to the discharge grate. The calculation of the maximum discharge rate, $d_{0}$, is detailed in an earlier paper (Apelt et al., 2002b) and elsewhere (Napier-Munn et al., 1996; Apelt, 2007).

Equation (8) provides no information about the material in the rock charge larger than the grate aperture size $\left(x_{g}\right)$. Apelt et al. (2002b) detail the estimation of the rock charge for particle sizes greater that the grate aperture size. The estimation involves the solving of a system of equations and utilises the assumption that the rock charge size distribution may be approximated by a Rosin-Rammler distribution and the rock charge fraction estimate from the next step (Step 3).

\section{Water}

The SAG mill water charge, $S M R C_{w}[\mathrm{t}]$ may be calculated as follows:

$$
S M R C_{w}=\frac{S M D C_{t p h_{-} l}}{d_{0}}
$$




\section{Step 3: Total Charge and Ball Charge Filling Levels}

SAG mill fractional total filling $\left(J_{t}\right)$ and ball filling $\left(J_{b}\right)$ are determined by solving the powerdraw or mill weight residuals given mill power draw or weight process measurements as inputs. SAG mill fractional rock charge filling $\left(J_{r}\right)$ is calculated by difference of the total and ball charge fractions, see Equation (11).

$$
J_{r}=J_{t}-J_{b}
$$

A residual can be constructed for each powerdraw and weight measurement. Both residuals can be reduced to equations in total $\left(J_{t}\right)$ and ball $\left(J_{b}\right)$ charge fractions. Solution for the two unknown charge fractions is achieved using a constrained nonlinear optimisation algorithm (e.g., the fmincon function in MATLAB optimisation toolbox). The residuals are solved with the complementary residual and the ball charge upper limit, see Equation (12), as inequality constraints. The ball charge must be less than or equal to the total charge:

$$
J_{b} \leq J_{t}
$$

For the powerdraw residual, $F_{k W}[\mathrm{~kW}]$, see Equation (13), the charge fractions are determined to equate the calculated powerdraw solution, $P_{\text {Gross }}[\mathrm{kW}]$, with the mill powerdraw measurement, $M V_{k W}[\mathrm{~kW}]$. Details of the powerdraw calculation are found in an earlier paper (Apelt et al., 2001a) and elsewhere (NapierMunn et al., 1996; Apelt, 2007).

$$
F_{k W}=M V_{k W}-P_{\text {Gross }}=0
$$

For the mill weight residual, $F_{\text {weight }}[\mathrm{t}]$, see Equation (14), the charge fractions are determined to equate the calculated mill weight $\left(M_{\text {shell }}+M_{\text {kidney }}\right)$ [t] with the actual mill weight measurement $M V_{\text {weight }}[\mathrm{t}]$. Details of the mill weight calculation, particularly the kidney weight, $M_{\text {kidney }}[\mathrm{t}]$, are found in earlier papers (Apelt $e t$ al., 2001a, Apelt et al., 2002b). The shell weight, $M_{\text {shell }}[\mathrm{t}$ ], can be estimated from plant knowledge or data, calculated according to mill dimension and lining specifications, or, be the result of a dynamic model of mill interior lining, as detailed in an earlier paper (Apelt et al., 2002a).

$$
F_{\text {weight }}=M V_{\text {weight }}-M_{\text {shell }}-M_{\text {kidney }}=0
$$

\section{Step 4: SAG Mill Total Feed}

SAG mill total feed $(S M T F)$ is calculated by mill model inversion.

\section{Solids Balance}

The solids component of the SAG mill total feed (SMTF/smtf) is estimated by the inversion of the Whiten steady state perfectly mixed mill model (Whiten, 1974), see Equation (15). The perfectly mixed mill model is described elsewhere (Valery Jnr and Morrell, 1995; Napier-Munn et al., 1996; Apelt et al., 2002b; Apelt, 2007). The use of the steady state perfectly mixed mill model provides a valid estimate of the total mill feed, providing the calculation time between the discharge and charge estimates and the total 
mill feed estimate is relatively short. If the calculation time is short, the dynamics of the mill rock charge may be disregarded.

$$
\mathrm{SMTF}_{i}=S M D C_{i}-\sum_{j=1}^{i-1} r_{j} \operatorname{SMRC}_{j} a_{i j}+\left(1-a_{i i}\right) r_{i} \operatorname{SMRC}_{i}
$$

where $S M T F_{i}$ is the mass of SAG mill total feedrate in size $i$ [t/hr], $S M D C_{i}$ is the mass of the SAG mill discharge solids in size $i[\mathrm{t} / \mathrm{hr}], S M R C_{i}$ is the mass of the SAG mill rock charge solids in size $i[\mathrm{t}], r_{i}$ is the breakage rate of particles in size $i\left[\mathrm{hr}^{-1}\right], a_{i j}$ is the appearance function of particles appearing in size $i$ (a function of the breakage distribution of particles in sizes $\geq$ size $i)$ [fraction] and $\left(1-a_{i i}\right)$ is the fraction of particles selected for the breakage size $i$ ) [fraction].

The appearance function, $a_{i j}$, is determined utilising information from the previous steps regarding the rock and ball charges fractions and size distributions and rock breakage parameters. The breakage rate function, $r_{i}$, is determined from the ball charge information also and the estimate of the recycle ratio of $-20+4 \mathrm{~mm}$ material and fresh feed eighty percent passing size $\left(F_{80}\right)$ from the previous time step (JKTech, 1994).

\section{Water Balance}

SAG mill total feed water is determined from the steady state balance for the water:

Water In = Water Out

$$
\operatorname{SMTF}_{w}=\mathrm{SMDC}_{w}
$$

The water entering the mill $S M T F_{w}[\mathrm{t} / \mathrm{hr}]$ is equal to the water in the SAG mill discharge stream $S M D C_{w}$ $[\mathrm{t} / \mathrm{hr}]$, determined in Step 1.

\section{Step 5: Oversize Crusher Product and Primary Cyclone Underflow}

Oversize crusher product $(O S C P)$ and primary cyclone underflow (PCUF) are calculated by the direct application of the crusher and cyclone simulation models.

\section{Oversize Crusher Product (OSCP/oscp)}

The oversize crusher product estimate, OSCP/oscp, is determined by applying the crusher model developed at the Julius Kruttschnitt Mineral Research Centre, (Whiten, 1972; JKTech, 1994; Napier-Munn et al., 1996), see Equation (17), to the estimate of the oversize crusher feed, OSCF/oscf, determined in Step 1.

$$
O S C P=(1-C) \cdot(1-B C)^{-1} \cdot O S C F
$$

where $O S C P$ is the crusher product by size [t/hr], OSCF is the crusher feed by size [t/hr], $B$ is the crusher breakage distribution function [fraction] (determined from lab breakage test information) and $C$ is the crusher probability of breakage function [fraction] (determined utilising crusher specifications and model parameters from plant survey data). 
The primary cyclone underflow estimate, $P C U F / p c u f$, is determined by applying the Nageswararao model (Napier-Munn et al., 1996), to the primary cyclone feed, PCFD/pcfd, determined in Step 1. The model is comprised of several equations that predict cyclone operating pressure $(P)$, corrected fifty percent passing size $\left(d_{50 c}\right)$, water recovery to underflow $\left(R_{f}\right)$, feed slurry recovery to underflow $\left(R_{v}\right)$ and the efficiency to overflow $\left(E_{o a}\right)$. These equations, detailed elsewhere (Napier-Munn et al., 1996; Apelt, 2007), are functions of cyclone geometry, process conditions, and efficiency curve parameters fitted from plant data.

\section{Step 6: SAG Mill Fresh Feed}

SAG mill fresh feed $(S M F F)$ and size distribution $(s m f f)$, including the feed size indicators $\left(F_{80} \ldots F_{20}\right)$, are calculated by subtracting oversize crusher product $(O S C P)$ and the primary cyclone underflow to SAG mill (PCUS) from the SAG mill total feed (SMTF) stream. The fresh feed size distribution (smff) and passing sizes $\left(F_{80} \ldots F_{20}\right)$ are calculated in the process.

$$
\begin{aligned}
& S M F F_{t p h_{-} s}=S M T F_{t p h_{-} s}-O S C P_{t p h_{-} s}-\left(1-P C_{s p l i t}\right) P C U F_{t p h_{-} s} \\
& S M F F_{t p h_{-} l}=S M T F_{t p h_{-} l}-O S C P_{t p h_{-} l}-\left(1-P C_{s p l i t}\right) P C U F_{t p h_{-} l}-M V_{F D_{-} H 2 O} S G_{l} \\
& s m f f=\frac{S M T F_{t p h_{-} s} s m t f-O S C P_{t p h_{-} s} O s c p-\left(1-P C_{s p l i t}\right) P C U F_{t p h_{-} s} p c u f}{S M T F t_{p h_{-} s}-O S C P_{t p h_{-} s}-\left(1-P C_{s p l i t}\right) P C U F_{t p h_{-} s}}
\end{aligned}
$$

where $S M F F_{\text {tph_s }}$ is the SAG mill fresh feed solids feedrate [t/hr], $S M F F_{t p h \_l}$ is the SAG mill fresh feed liquid feedrate [t/hr], smff is the SAG mill fresh feed size distribution [\%retained w/w], $S M T F_{t p h \_s}$ is the SAG mill total feed solids feedrate [t/hr], $S M T F_{t p h_{-} l}$ is the SAG mill total feed liquid feedrate [t/hr], smtf is the SAG mill total feed size distribution [\% retained $\mathrm{w} / \mathrm{w}], M V_{F D_{-} H 2 O}$ is the SAG mill feed addition water process measurement $\left[\mathrm{m}^{3} / \mathrm{hr}\right], S G_{l}$ is the process water specific gravity $\left[\mathrm{t} / \mathrm{m}^{3}\right]$ and $\left(1-P C_{\text {split }}\right)$ is the recycled split-fraction of the primary cyclone underflow [fraction]. The split-fraction of primary cyclone underflow to the ballmill, $P C_{\text {split }}$ ) [fraction], is calculated after a completing an overall SAG mill solids mass balance, as follows:

$$
\begin{aligned}
& P C U S_{t p h_{-} s}=S M D C_{t p h_{-} s}-O S C P_{t p h_{-} s}-S M F F_{t p h_{-} s} \\
& P C_{s p l i t}=1-\frac{P C U S_{t p h_{-} s}}{P C U F_{t p h_{-} s}}
\end{aligned}
$$

where $S M D C_{t p h_{\_} s}$ is the solids component of the SAG mill discharge [t/hr], $O S C P_{t p h \_s}$ is the solids component of the oversize crusher product [t/hr], $S M F F_{t p h_{-} s}$ is the solids component of the SAG mill fresh feed [t/hr] and $P C U F_{t_{p h} \_}$is the solids component of the primary cyclone underflow [t/hr]. The SAG mill fresh feed estimate is dependent on the split-fraction, which itself requires the SAG mill fresh feed estimate. This circular dependency is resolved by utilising the split-fraction from the previous time-step in the calculation of the SAG mill fresh feed, or, the plant measurement of SAG mill feedrate and a moisture content assumption.

The estimate of the SAG mill fresh feed eighty percent passing size, $F_{80}$, is determined by interpolation of the estimate of the size distribution, smff, at the $80 \%$ mark. Similarly, the sixty, forty and twenty percent passing sizes $\left(F_{60}, F_{40} \& F_{20}\right.$, respectively) can be determined. 


\section{RESULTS AND DISCUSSION}

Previously, the inferential model results were assessed by comparison to the results of a process simulation model and found to give satisfactory results and thus deemed valid (Apelt et al., 2002b). Here the inferential models are furher validated on process data and incorporated in a multi-variable, model predictive control $(M P C)$ simulation.

\section{Inferential Model Validation on Process Data}

The inferential models described above were validated using data collected during the execution of the SAG Mill Control Project (Romagnoli et al., 1997) on site at Northparkes Mines in late 1997. The twominute data was augmented by the the Module 1 Grinding Logsheets and Shift Communication Book Sheets for the period (8 - 16 October 1997).

The MATLAB-Simulink model files were configured to read in the plant data from a master data file, collated from the various data files for this express purpose. The nine days worth of data was read from the master data file spreadsheet and processed by the inferential measurement models. The results were written out to text files, the content of which was pasted a master spreadsheet file for collation and graphing. From the significant volume of results generated, specific periods of the results were selected that highlight the performance of the key models.

\section{SAG Mill Charge Estimates}

The first set of results are for 8 October 1997. The Grinding Log Sheet recorded that there ball charging only occurred during day-shift (08:00 - 16:00 hrs). Figures 2 and 3 illustrate the inferential model of the ball charge fraction, $J_{b}$, capturing the ball charging that occurs during the day shift. The model estimates the ball charge fraction firstly rising from 0.10 to 0.11 during day shift, while ball charging takes place. There is no further ball charging during afternoon shift and the model estimates fall back to the 0.10 level, plausibly due to ball charge wear and ball ejection (worn or broken balls pass through the discharge grates).

The trends of the ball, rock and total charge estimates, $J_{b}, J_{r}$ and $J_{t}$, respectively, and the feed size estimate, $F_{80}$, are five (5) sample averages. The noise prevalent in the charge estimates is due to the noise in the mill powerdraw signal. The powerdraw signal, even as a two (2) minute sample, contains significant noise. This noise translates to the noise in the estimates. Further model refinement should therefore incorporate a degree of signal filtering to eliminate most of this noise.

A mill inspection was conducted on 14 October 1997 as part of the data collection phase of the SAG Control Project (Romagnoli et al., 1997). The Shift Communication Book from this date recorded the results of the mill inspection. The author participated in this inspection and, visually, the total charge fraction $\left(J_{t}\right)$ was $0.17(17 \%)$ and the ball charge fraction $\left(J_{b}\right)$ was $0.12(12 \%)$.

The prevailing conditions, at the time of the mill inspection, and the inferential charge measurement model results are shown in Figures 4 and 5, respectively. The inferential measurement model results of $J_{t}=0.25$ and $J_{b}=0.08$, although in the ballpark, do not exhibit excellent agreement with the mill inspection results. The total charge estimate, $J_{t}$, is some $50 \%$ above and the ball charge estimate, $J_{b}$, is approximately $33 \%$ below the mill inspection results.

Although the mill inspection was conducted on a purely-visual basis, and, as such, is subject to a degree of error, measurements errors of 30 to $50 \%$ are not expected. Therefore, the mill charge measurement models contain significant error. Although significant, this level of error is not considered a major concern in this instance. The estimates arise from the mill powerdraw and weight residuals, Equations (13) and (14), respectively. These equations have parameters that are adjusted to better fit the plant data. However, due 
to the absence of comprehensive plant survey information from October 1997, the parameters were not adjusted from the original values obtained in January 1997, some nine (9) months earlier and presumably out of date. Furthermore, the aspect considered most important in this instance, is the ball-park agreement and the ability of the model results to trend in a sensible manner, which was demonstrated in the analysis of the 8 October 1997 results above. In any case, in controlling a variable, the nature in which it trends is equally and often more important as its absolute value.

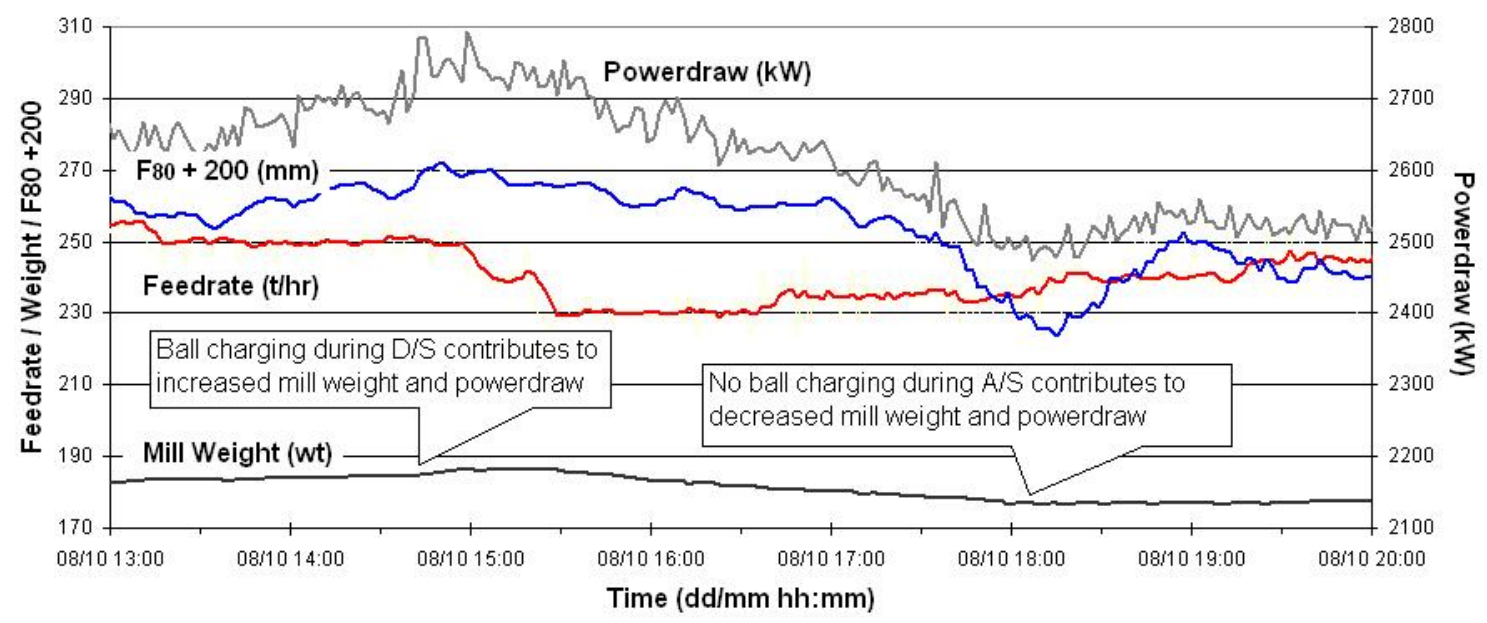

Fig.2 Results for 8 October 1997: Mill powerdraw and weight increase with ball charging and decrease when charging is ceased. ( $\mathrm{F}_{80}$ results are shown also)

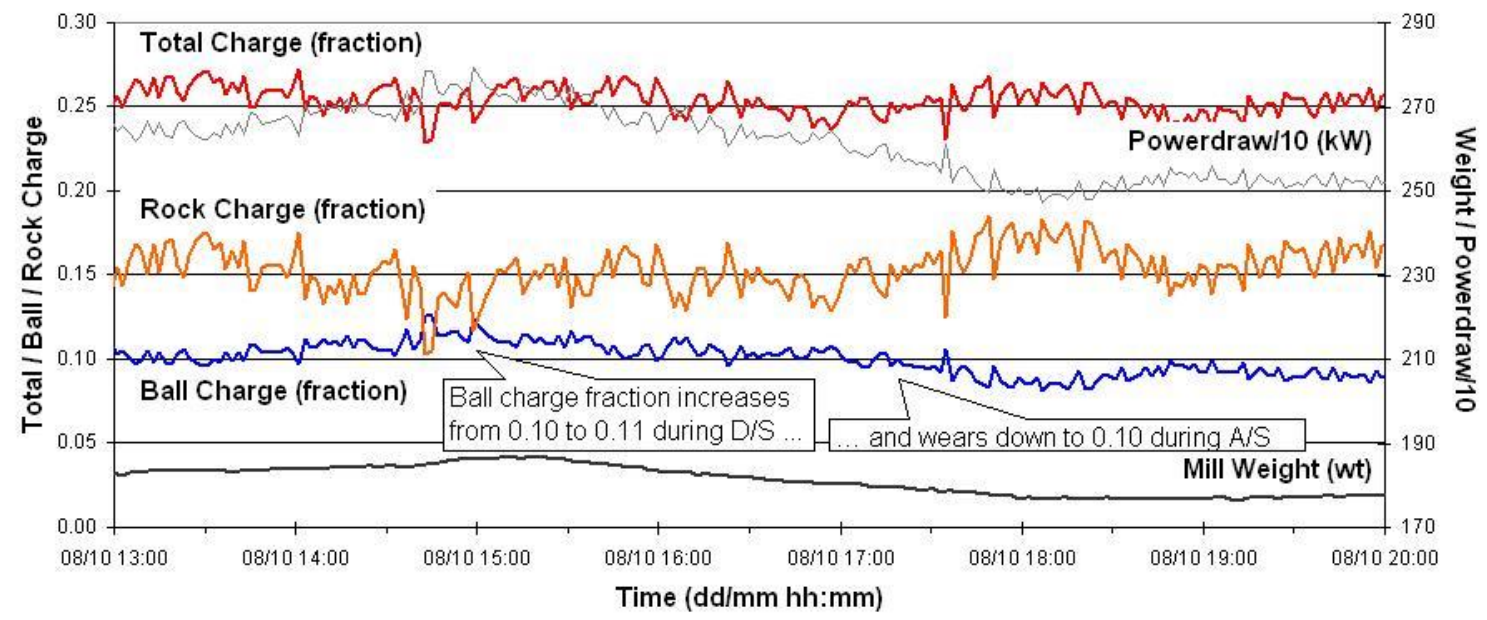

Fig.3 Results for 8 October 1997: Ball charge $\left(\mathrm{J}_{\mathrm{b}}\right)$ increases during day shift and wears away in the absence of ball charging during afternoon shift. 


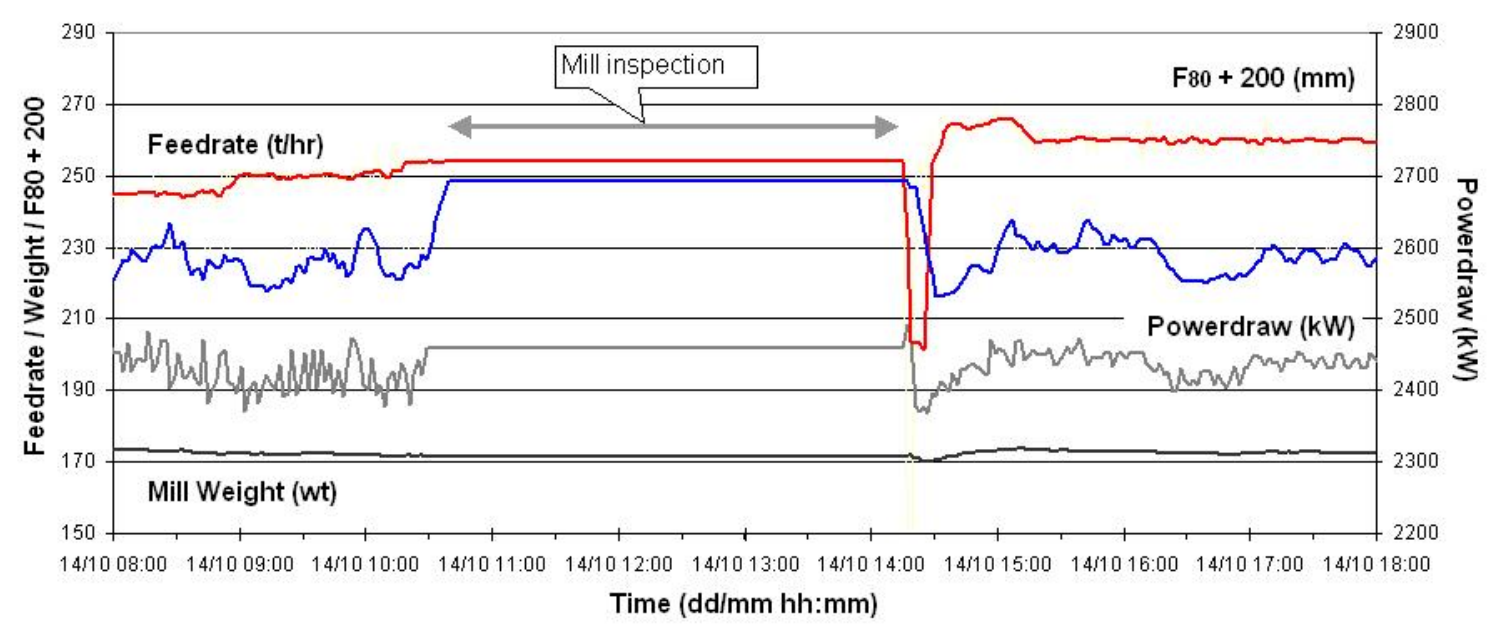

Fig.4 Results for 14 October 1997: Mill powerdraw and weight prevailing at the time of the mill inspection.

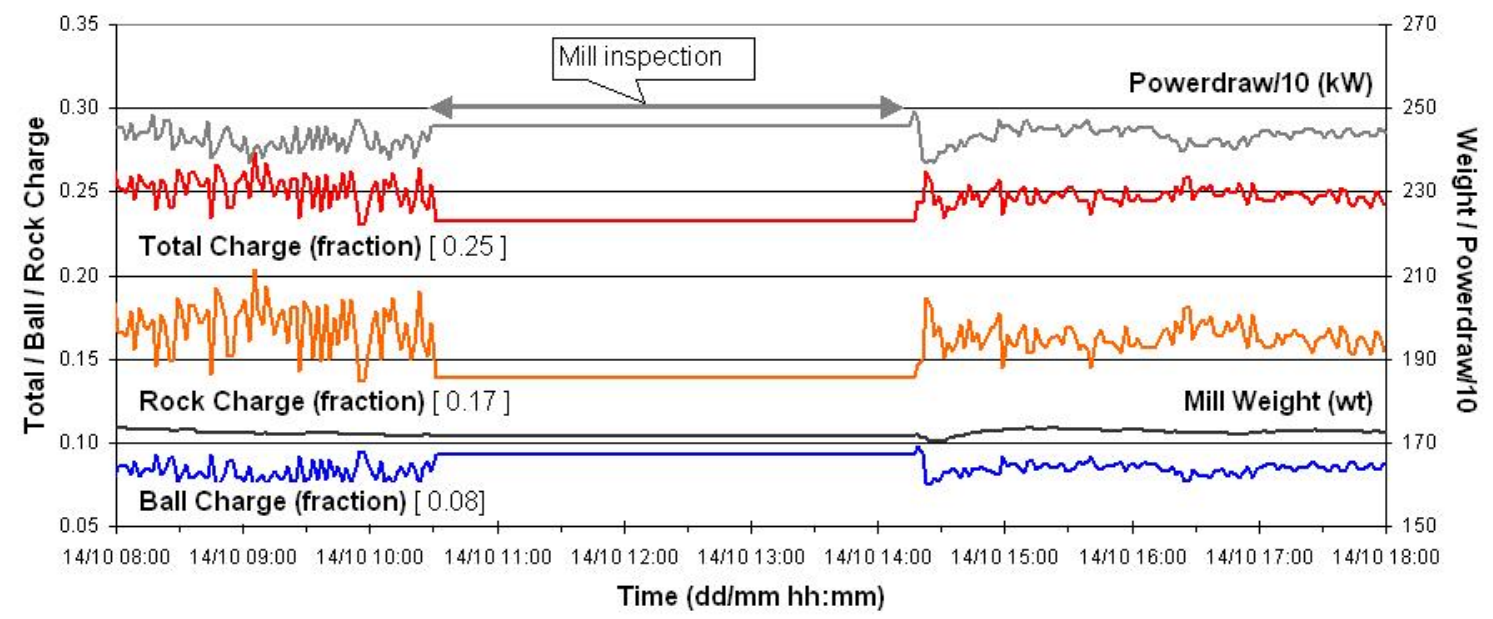

Fig.5 Results for 14 October 1997: Mill charge estimates for the time of the mill inspection. Total charge (Jt): 0.25, Ball charge (Jb): 0.08 . 


\section{Feedsize Estimate}

During the afternoon shift of 9 October 1997, the mill control room operator noted that the feed size was increasing. This observation is captured well by the inferential measurement model of the feed size via the $F_{80}$ measurement estimate, see Figure 6 . The feed size increase causes increases in mill powerdraw and mill weight and is presumably due to increasing hardness. To accommodate the feed size increase, the operator decreases the feedrate.

The absolute value of the actual $F_{80}$ trend on 9 October 1997 is not known. However, the utilisation of the $F_{80}$ inferential measurement model within a controller structure would still be possible, since the way the model measurement trends is the key characteristic here. Suitable high and low limits may be set nominally or via a calibration procedure to accommodate any offset between model prediction and plant reality.

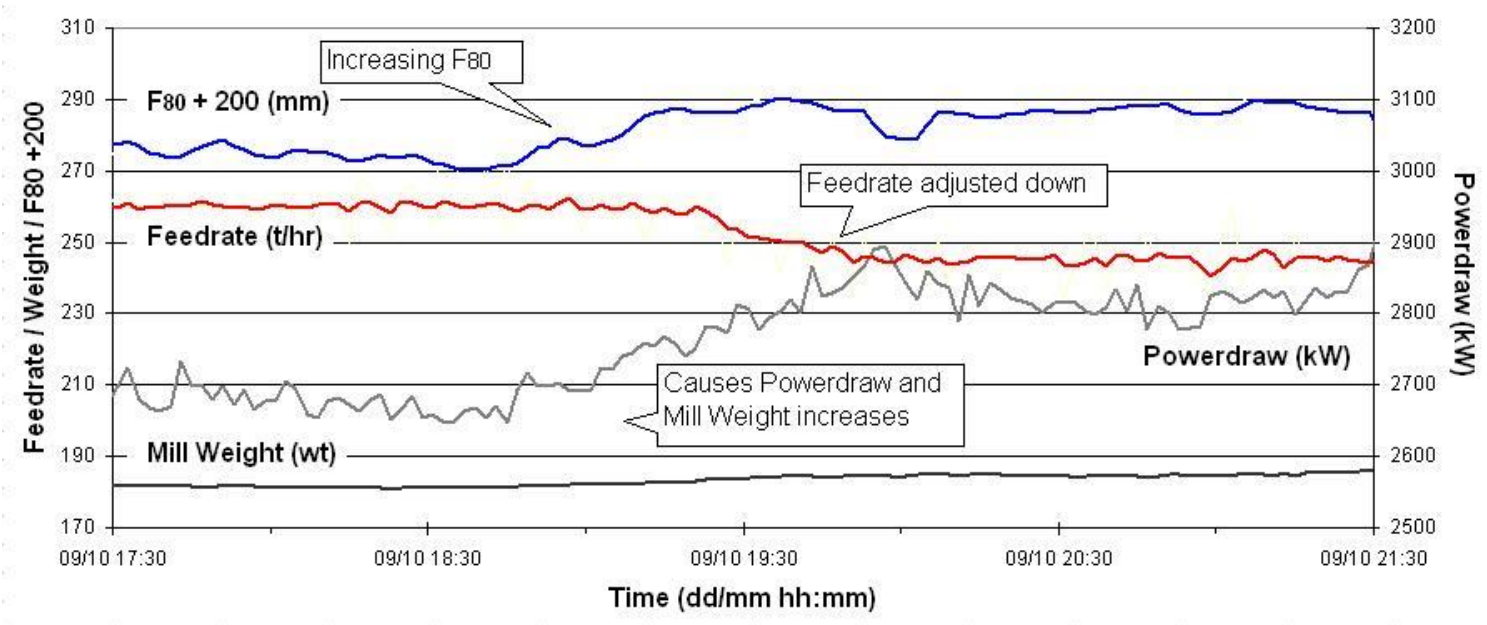

Fig.6 Results for 9 October 1997: $\mathrm{F}_{80}$ model increases as observed by the Control Room Operator.

\section{Model Limitations}

Although the results produced by the inferential measurement models are encouraging overall, two model limitations have been noted, namely:

1. the mill charge estimates do not capture feedsize and density changes

2. the mill charge and feedsize estimates behave unusually when the oversize crusher goes off-line Also during afternoon shift on 9 October 1997, the mill feed density was increased two percent to stop shell-bolts leaking. This change was made at approximately 19:00 hrs. Referring to Figure 7, one observes that at 19:00 hrs there is increases in mill powerdraw and mill weight. Increasing the feed density would cause an increase in the residence time of the ore in the mill. The increased ore retention would register in increased mill weight and powerdraw, which occurs in this case. The inferential models do not, however, behave in the expected way: increases in total and rock charges and a constant ball charge. In contrast, increases in the plant measurements cause ball charge estimate increases and the rock and total charge estimate decreases. Feedsize was increasing over the afternoon shift, as discussed above. The total and rock charges estimates should have increased on account of such a disturbance in feedsize alone. This incorrect behaviour is a model limitation. Further research could determine the reason such behaviour occurs. 


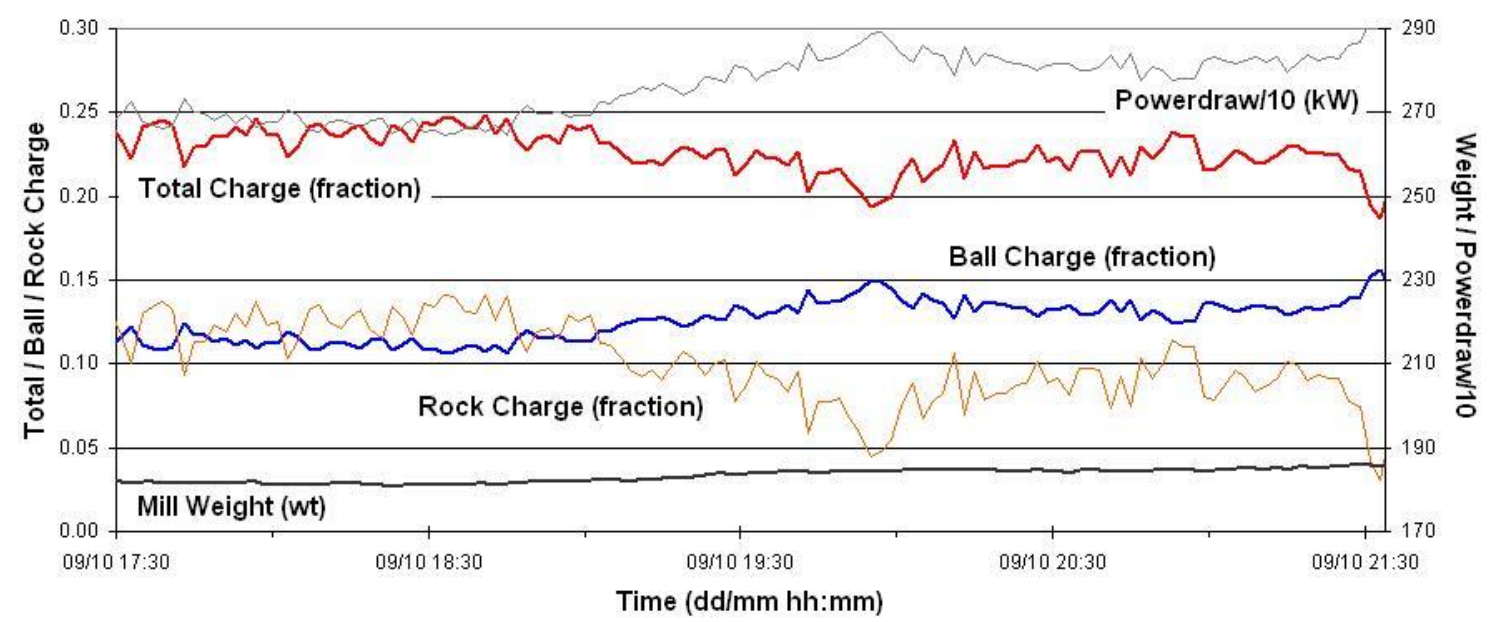

Fig.7 Results for 9 October 1997: Increase in mill density is thickened causes increases in mill powerdraw and weight, which affects the mill charge estimates.

The second limitation was observed when problems were experienced with the oversize crusher. For three hours during day shift on 15 October 1997, the oversize crusher was set offline and by-passed by the oversize crusher feed recycle stream. The problems with the oversize crusher are unexpectedly reflected in the feed size $\left(F_{80}\right)$ estimate, see Figure 8 . When the oversize crusher is off-line, the $F_{80}$ estimate increases markedly. This is not to be expected since the recycled material does not affect the physical properties of the fresh feed stream. The build up of critically-sized within the mill, caused by direct-recycling of the crusher feed, would require decreases in fresh feedrate to address increases in mill powerdraw and weight. These process changes are evident in Figure 8.

The oversize crusher outage also affects the mill charge estimates, see Figure 9 . While the oversize crusher is off-line, the charge inferential measurement model estimates an elevated ball charge $\left(J_{b}\right)$ and depressed total $\left(J_{t}\right)$ and rock $\left(J_{r}\right)$ charges. In reality, the ball charge level would have remained constant and the rock and total charges would have increased. This incorrect behaviour is a model limitation and should be duely noted when treating results.

The feedsize estimate is at the end of a chain of calculations, Step 6 in the calculation sequence described in the previous Section. The results of the calculations in the chain and assumptions made in them affect the feedsize estimate. All of the preceding steps contain model inaccuracy and errors introduced by simplifying assumptions. Although the primary cyclones and oversize crusher are downstream from the feed stockpile, the nature of the feedsize estimate model means that the primary cyclone and oversize crusher streams (and all other streams in between) influence the feedsize estimate.

The model limitation that this unusual behaviour represents could potentially serve a useful purpose. This model feature could potentially be utilised as a process monitoring and diagnostic tool to alert the process operators of the advent of unusual process conditions. Additionally, if the models were part of a controller, normal plant operating status checks would have switched the controller off, thus avoiding any undue control action. Future research could further investigate the process diagnosis potential of the inferential measurement models. 


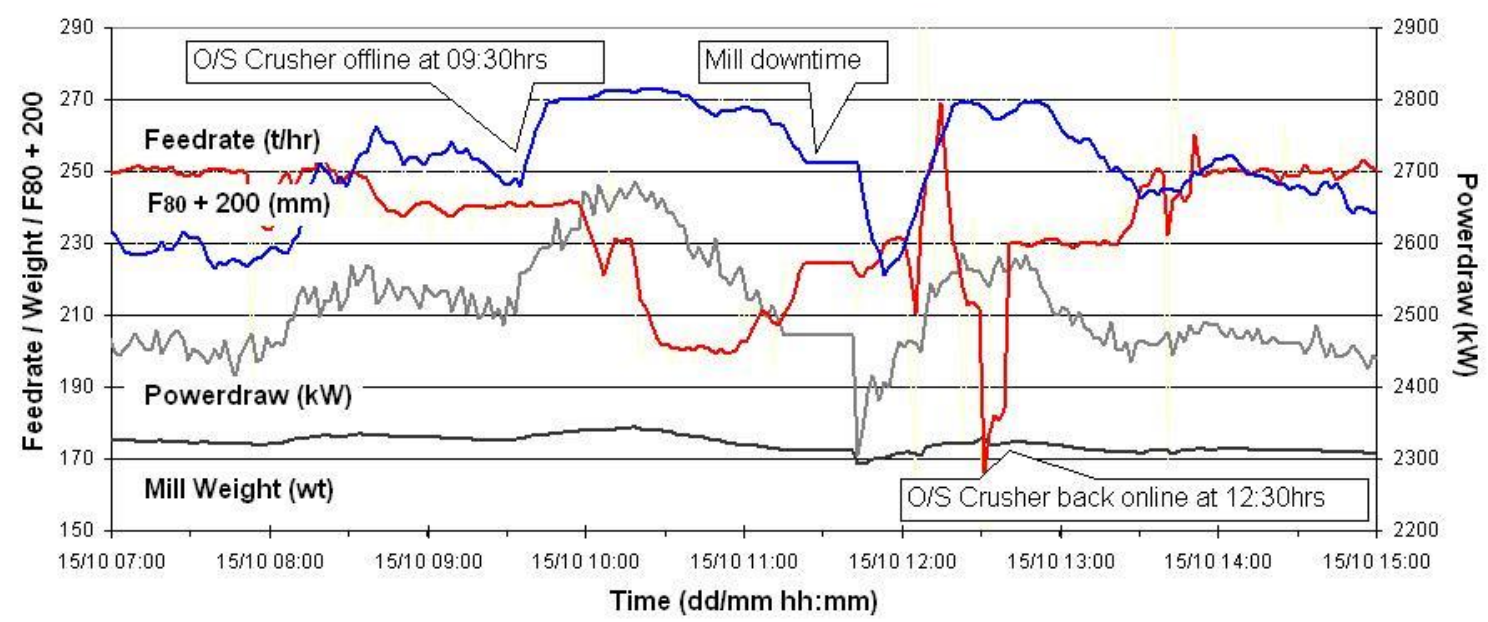

Fig.8 Results for 15 October 1997: Oversize crusher going offline affects feed size $\left(\mathrm{F}_{80}\right)$ estimate.

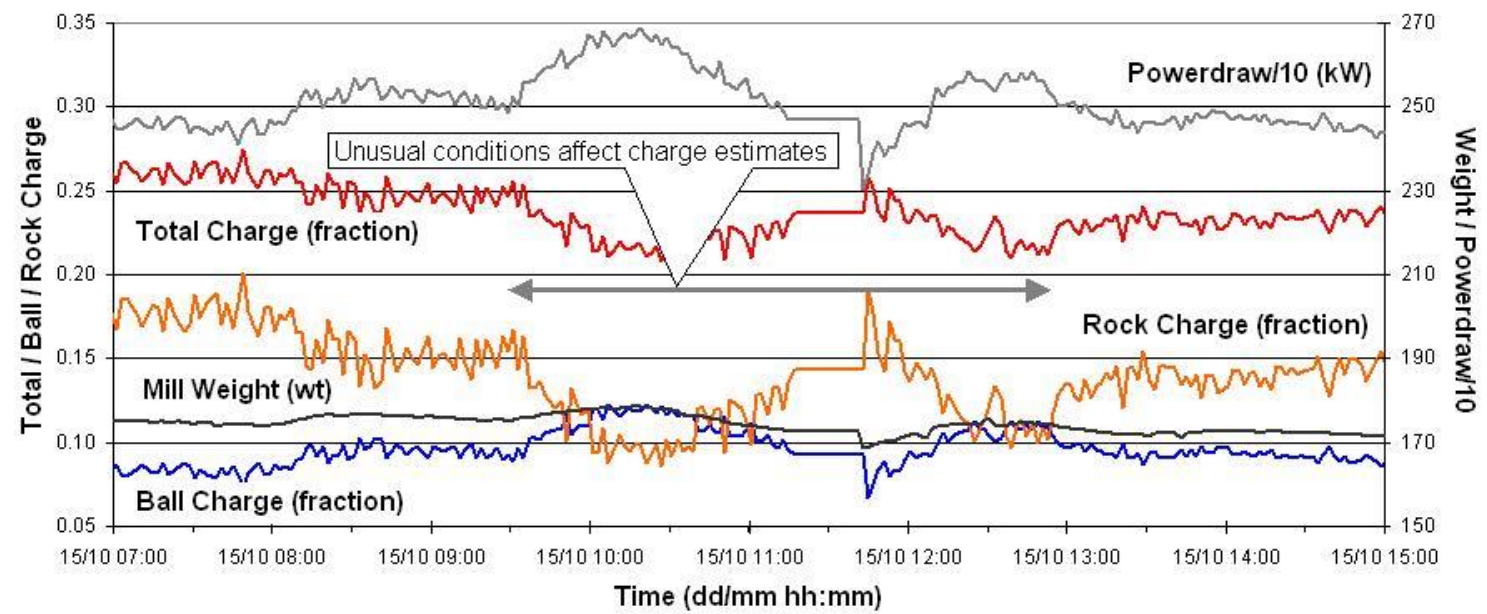

Fig.9 Results for 15 October 1997: Oversize crusher going offline also affects the mill charge estimates.

The mill charge and feedsize estimate model results were assessed previously by comparison to the results of a process simulation model and deemed valid on account that the results were satisfactory (Apelt et al., $2002 b$ ). The positive performance on plant data here, whilst highlighting some limitations, reinforces the validity of the models.

\section{Model Characteristics}

Sensitivity analyses were conducted on the inferential measurement models. Original results were reported in an earlier paper (Apelt et al., 2001a). Further analysis was effected by ramping the key model inputs up and down ten percent $( \pm 10 \%)$. Table 1 contains the results for model sensitivity to movements in powerdraw, weight and oversize crusher feedrate (scats). Note that the powerdraw results are for changes of $100 \mathrm{~kW}$. Also note that the two remaining model inputs, SAG mill feedrate and SAG mill feedwater addition, had minimal to no effect on the estimates. 
TABLE 1 Model Sensitivity Analysis Results

\begin{tabular}{|ll|c|c|c|c|}
\hline & & $\begin{array}{c}\text { Total Charge } \\
J_{t}\end{array}$ & $\begin{array}{c}\text { Ball Charge } \\
J_{b}\end{array}$ & $\begin{array}{c}\text { Rock Charge } \\
J_{r}\end{array}$ & $\begin{array}{c}\text { Feedsize } \\
F_{80}\end{array}$ \\
\hline \multirow{3}{*}{ Model Input } & (units) & $\Delta J_{t}$ & $\Delta J_{t}$ & $\Delta J_{t}$ & $\Delta J_{t}$ \\
\cline { 3 - 6 } & $\begin{array}{c}\Delta \text { Input } \\
(\% / \text { units })\end{array}$ & $\begin{array}{c}\Delta \text { Input } \\
(\% / \text { units })\end{array}$ & $\begin{array}{c}\Delta \text { Input } \\
(\% / \text { units })\end{array}$ & $\begin{array}{c}\Delta \text { Input } \\
(\mathrm{mm} / \text { units })\end{array}$ \\
\hline \multirow{2}{*}{$\begin{array}{l}\text { Powerdraw } \\
\text { Weight }\end{array}$} & $(\mathrm{kW})$ & -4 & 2 & -6 & 0.2 \\
Scats & $(\mathrm{t})$ & 1 & -0.4 & 2 & -2.2 \\
& $(\mathrm{t} / \mathrm{hr})$ & 0.1 & 0.0 & 0.0 & 0.8 \\
\hline
\end{tabular}

\section{Powerdraw sensitivity}

The sensitivities of the total, ball and rock charge fraction estimates to a $100 \mathrm{~kW}$ change in powerdraw are $-4 \%, 2 \%$ and $-6 \%$ volume, respectively. Taken in isolation, the magnitudes of the sensitivities appear near-credible. However, perhaps half of these figures is more realistic. The large sensitivities suggest the inferential models are be highly sensitive to changes in powerdraw. Reinforcing this finding is that all of the changes take place concurrently. That is, a $100 \mathrm{~kW}$ increase in powerdraw represents a $2 \%$ increase in ball charge volume and a $4 \%$ decrease in total charge volume (these in turn represent a $6 \%$ decrease in rock charge volume). Once again, figures half this magnitude would be more realistic, i.e., an increase in powerdraw of $100 \mathrm{~kW}$ could be expected to result from a $1 \%$ increase in ball charge volume and a $3 \%$ decrease in rock charge volume ( $2 \%$ increase in total charge volume).

This degree of sensitivity adds to the case for measurement filtering. The noise inherent in the measuring device plus the measurement noise of the tumbling charge within the mill warrants significant filtering, e.g., a five-minute moving average. The fact that the operating point does not move in large sudden steps attenuates the effect of the sensitivities also.

It should also be noted that an increase in powerdraw is likely to be accompanied by an increase in mill weight in the real plant. Therefore, changes in the charge estimates due to powerdraw changes would be tempered by changes in the mill weight. The sensitivities of the charge estimates to changes in mill weight are discussed below.

The feedsize $\left(F_{80}\right)$ estimate also exhibits a high degree of sensitivity to changes in powerdraw: a $100 \mathrm{~kW}$ change in powerdraw will result in a $20 \mathrm{~mm}$ change in feedsize estimate. A change in the feedsize of 2 to $10 \mathrm{~mm}(10-50 \%)$ would be a more realistic cause of a $100 \mathrm{~kW}$ change in powerdraw.

\section{Weight sensitivity}

The sensitivity of the total charge fraction estimate to an increase of 1 tonne in mill weight is an increase in the total charge of $1 \%$ volume. The sensitivities of the ball and rock charge fraction estimates to a 1 tonne change in mill weight are $-0.4 \%$ and $2 \%$ volume, respectively.

These sensitivities to weight changes are more credible than those for powerdraw changes. Filtering the mill weight measurement to remove measurement noise and noise due to the tumbling charge is still warranted. A five-minute moving average could be applicable here also. Further research could investigate the appropriate filtering for both the weight and powerdraw signals.

The feedsize $\left(\mathrm{F}_{80}\right)$ estimate exhibits an unusual degree of sensitivity to changes in mill weight: a 1 tonne increase in mill weight will result in a $-2 \mathrm{~mm}$ change in feedsize estimate. A decrease in feedsize generally 
accompanies a decrease in feed ore hardness. A decrease in mill weight would be expected as the rock charge would decrease since the rock breaks more easily. The behaviour of the estimate is unusual and is discussed further below in relation to the breakage rates in the SAG mill.

\section{$\underline{\text { Scats sensitivity }}$}

Referring to Table 1, the mill charge estimates are weakly affected by changes in the oversize crusher feedrate (scats). One would expect increased scats could reflect an increase in the rock charge, a decrease in the ball charge (by increased wear) and an increase in the total charge fraction overall, as is the case here. However, the sensitivity here is not attributed to such processing conditions. Here, the sensitivity is due to the nature of the models. The scats tonnage and an assumed particle size distribution are used in the estimate of the SAG mill discharge stream. The discharge stream affects the mill rock charge estimate, which in turn, affects the feed estimates. Hence, changes in the scats cascade upstream through the mill charge inferential models to the feedsize inferential model. This model limitation should be noted when treating results.

A $10 \mathrm{t} / \mathrm{hr}$ increase in scats will result in an $8 \mathrm{~mm}$ increase in the feed $\mathrm{F}_{80}$ estimate. In the real plant, an increase in scats would be expected with an increase in feedsize (and ore hardness). The model captures this to a degree in that with an increased scats tonnage, the SAG mill discharge stream, the mill rock charge and total feed and fresh feed estimates are all more coarse. However, the feedsize estimate is also influenced by the subtraction of the oversize crusher product from the total mill feed stream. The assumptions made for the oversize crusher product size distribution may result in a fine, closely-sized stream being subtracted from the total mill feed stream. Thus, rendering the fresh feed more coarse size estimate.

\section{Feedsize sensitivity and calculation sequence}

Ramping the key model inputs up and down ten percent has highlighted the sensitivity of the feedsize estimate to the calculation sequence.

- Firstly, estimates of the primary cyclone feed and oversize crusher feed are added together to estimate the SAG mill discharge stream.

- In Step 2, the discharge stream is passed through the grate classification function to estimate the bottom of the SAG mill rock charge size distribution, the coarser size fractions estimated from extrapolation of a Rosin-Rammler size distribution.

- The total, ball and rock charge fractions are estimated from the mill powerdraw and weight measurements in Step 3. In Step 4, the rock and ball charge estimates, the breakage parameters are estimated. The SAG mill total feed is estimated using these parameters, the rock charge fraction and size distribution estimates and the SAG mill discharge stream estimate.

- In Step 5, the oversize crusher product and primary cyclone underflow are estimated utilising the crusher and cyclone feed stream estimates and applying the crusher and cyclone models accordingly.

- Finally, in Step 6, an estimate of the SAG mill fresh feed is obtained by subtracting estimates of the oversize crusher product and primary cyclone underflow from the SAG mill total feed estimate.

Each of these steps contain model inaccuracy and error introduced by simplifying assumptions. Although the primary cyclones are several unit operations removed from the feed stockpile and their behaviour has no bearing on the stockpile feed, the nature of the feedsize estimate model means that the primary cyclone streams (and all other streams between) influence the feedsize estimate.

The model excitation also highlighted some unusual behaviour in the feedsize estimate when ramping the mill weight and powerdraw signals up and down. Considering the issues introduced by calculation 
sequence, several estimates and calculated model parameters were investigated to pin-point the origin of the unusual behaviour. Downstream of the SAG mill discharge, all estimates and parameters were coincident. The SAG mill rock charge size distribution was also constant. The varying SAG mill weight and powerdraw measurents resulted in changes in the total charge $\left(J_{t}\right)$ and ball charge $\left(J_{b}\right)$ estimates. These, in-turn, caused variation in the calculated parameters utilised to determine the appearance function $\left(a_{i j}\right)$, namely, the specific comminution energy $(E c s)$ and the high energy impact parameter $\left(t_{10}\right)$. The variation, however, appeared ordered and was not the cause of the unusual behaviour displayed in the feedsize estimate.

It was found that varying the mill weight and powerdraw $\pm 10 \%$ caused order-of-magnitude changes in the breakage rates, see Figure 10, via the the mill charge estimates. These large changes in the breakage rates propagated through to the fresh feed size estimate via the SAG mill total feed estimate, see Equation (15). Figure 11 shows SAG mill fresh feed size distribution. The significant differences are due to the breakage rates and result in a corresponding variation in feedsize $F_{80}$ estimate.

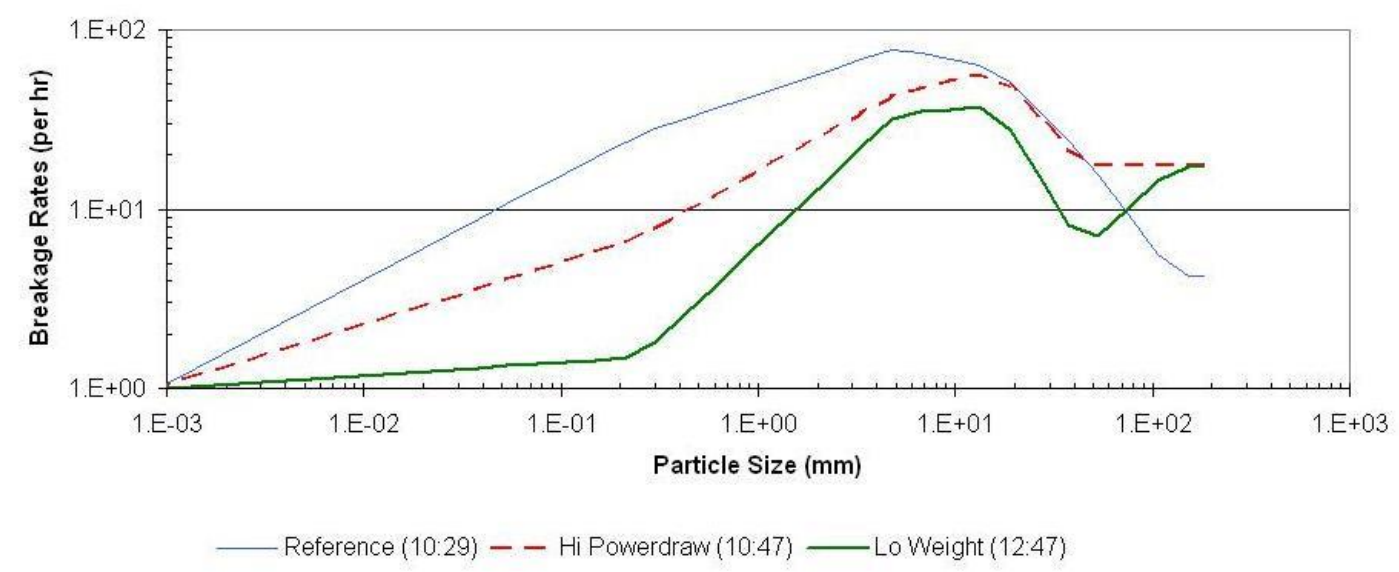

Fig.10 Breakage rate (ri) by size for reference, high-powerdraw and low mill weight conditions. Large differences between estimates. Order of magnitude differences in places.

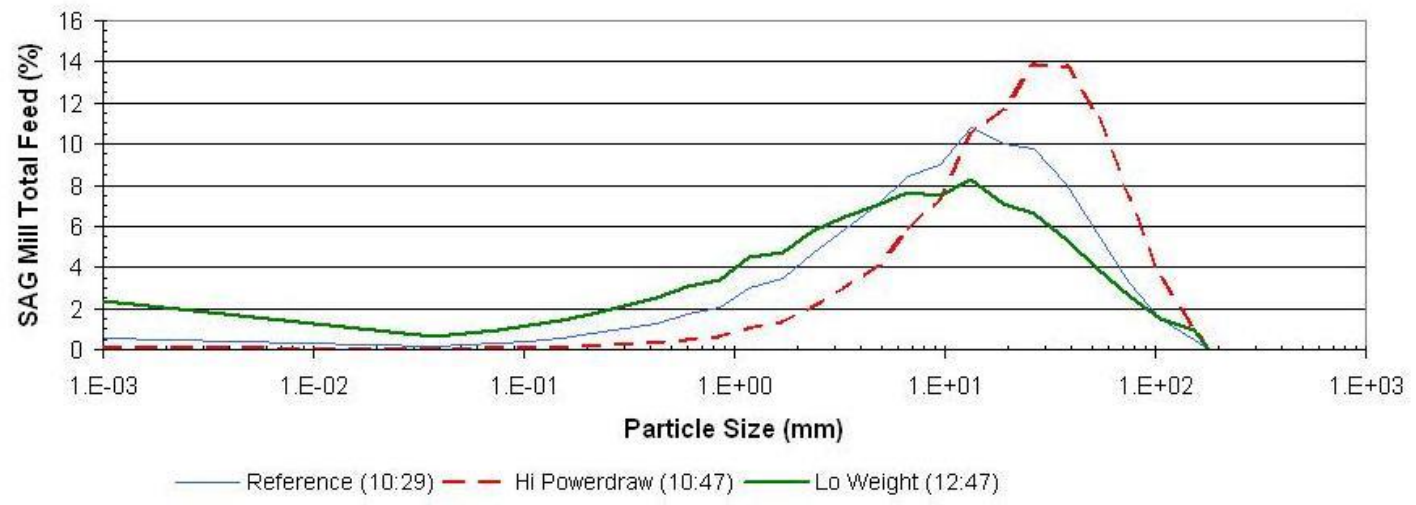

Fig.11 SAG mill total feed size distribution for reference, high-powerdraw and low mill weight conditions. Significant differences between estimates - as a result of the differring breakage rates. 
Previously, in the development and validation phase of the dynamic model of the SAG mill, Apelt (2007) described a high degree of model sensitivity to the SAG mill breakage rates, $r_{i}$, being encountered. "Small variations in the calculated breakage rates, $r_{i}$, resulted in the SAG mill rock charge diverging in an unbounded fashion from the initial steady state conditions."

This behaviour was attributed in part to errors introduced during the model fitting stage of the research, including the utilisation of linear interpolation methods instead of higher order methods. The behaviour was also likely to be characteristic of the breakage rate model itself since researchers at the Julius Kruttschnitt Mineral Research Centre (JKMRC) have experienced similar behaviour ("room for improvement" exists in the "key sub-process" of the "breakage rate relationships"). The JKMRC have also utilised a Kalman filter to estimate parameters to continually tune the model against on-line data (Morrell et al., 2001).

Inspection of the breakage rate equations, Equations (23) to (27), reveal that the breakage rates, $R I-R 5$ $\left[\mathrm{hr}^{-1}\right]$, are proportional to the exponential of the ball charge $\left(J_{b}\right)$.

$$
\begin{aligned}
& \ln (R 1)=\frac{\left(\mathrm{k}_{11}+\mathrm{k}_{12} \ln (\mathrm{R} 2)-\mathrm{k}_{13} \ln (\mathrm{R} 3)+\mathrm{J}_{\mathrm{B}}\left(\mathrm{k}_{14}-\mathrm{k}_{15} \mathrm{~F}_{80}\right)-\mathrm{D}_{\mathrm{B}}\right)}{\mathrm{S}_{\mathrm{b}}} \\
& \ln (\mathrm{R} 2)=\mathrm{k}_{21}+\mathrm{k}_{22} \ln (\mathrm{R} 3)-\mathrm{k}_{23} \ln (\mathrm{R} 4)-\mathrm{k}_{24} \mathrm{~F}_{80} \\
& \ln (R 3)=S_{a}+\frac{\left(\mathrm{k}_{31}+\mathrm{k}_{32} \ln (\mathrm{R} 4)-\mathrm{k}_{33} \mathrm{Rr}\right)}{\mathrm{S}_{\mathrm{b}}} \\
& \ln (\mathrm{R} 4)=\mathrm{S}_{\mathrm{b}}\left(\left(\mathrm{k}_{41}+\mathrm{k}_{42} \ln (\mathrm{R} 5)+\mathrm{J}_{\mathrm{B}}\left(\mathrm{k}_{43}-\mathrm{k}_{44} \mathrm{~F}_{80}\right)\right.\right. \\
& \ln (\mathrm{R} 5)=\mathrm{S}_{\mathrm{a}}+\mathrm{S}_{\mathrm{b}}\left(\mathrm{k}_{51}+\mathrm{k}_{52} \mathrm{~F}_{80}+\mathrm{J}_{\mathrm{B}}\left(\mathrm{k}_{53}-\mathrm{k}_{54} \mathrm{~F}_{80} \ln (\mathrm{R} 4)\right)-3 \mathrm{D}_{\mathrm{B}}\right)
\end{aligned}
$$

where $R 1 \ldots R 5$ are the base breakage rates [hr-1], $k i j$ are regression coeffcients based on data collected by the Julius Kruttschnitt Mineral Research Centre (JKTech, 1994) [dimensionless], $J_{B}$ is the mill volume occupied by grinding balls and associated voids [\%], $S_{a}$ is a mill speed (RPM) scaling factor [dimensionless], $S_{b}$ is mill fraction critical speed scaling factor [dimensionless], $D_{B}$ is a ball topsize scaling factor [dimensionless], and $R_{r}$ is recycle ratio of minus $20 \mathrm{~mm}$ - plus $4 \mathrm{~mm}$ material [dimensionless].

The functional dependence on equipment parameters (mill speed and ball size) and operating conditions (feed size, recycle ratio and ball charge level, $J b$ ) gives rise to the name of "variable rates model". The breakage rate function, $r_{i}$, is determined by interpolation for each particle size across the range of the five pairs of base breakage rates $(R 1 \ldots R 5)$ and "knot" sizes, which are selected to encompass the size distribution and capture important features of the breakage rate curve and (JKTech, 1994, Morrell and Morrison, 1996), such as the slower breaking rates of the critically sized material (that is discharged from the mill via pebble ports and recycled to the oversize crusher).

The high sensitivity of SAG mill feedsize estimate to the SAG mill breakage rates is a concern and should be duely noted. The exponential proportionality of the breakage rates to the ball charge fraction $\left(J_{b}\right)$ is the cause of the high sensitivity. Further research could investigate other formulations for estimating the breakage rates that eliminate this sensitivity whilst still capturing the critical features of the breakage rate curve. Filtering the mill powerdraw and weight signals specifically for the feedsize estimate could reduce the impact of measurement and process noise. A 15-minute rolling average could be utilised here. Feedsize changes typically occur over a longer time period, e.g., 15 - 30 minutes. Therefore, valuable information will not be lost whilst achieving a more reliable estimate. 


\section{$\underline{\text { Charge estimate correlation and contours }}$}

There is evidence of negative, proportional correlation between the ball charge estimate $\left(J_{b}\right)$ and the estimates of total charge $\left(J_{t}\right)$. Figure 12 illustrates the total and ball charge data. A linear-regression of the data is shown. The line of -0.9 slope has moderate variance (0.53). Approximately half of the variation in the total charge estimate is attributable to the variation in the ball charge estimate. Visual inspection suggests the data could form several steeper striations (with slope closer to -2 ).

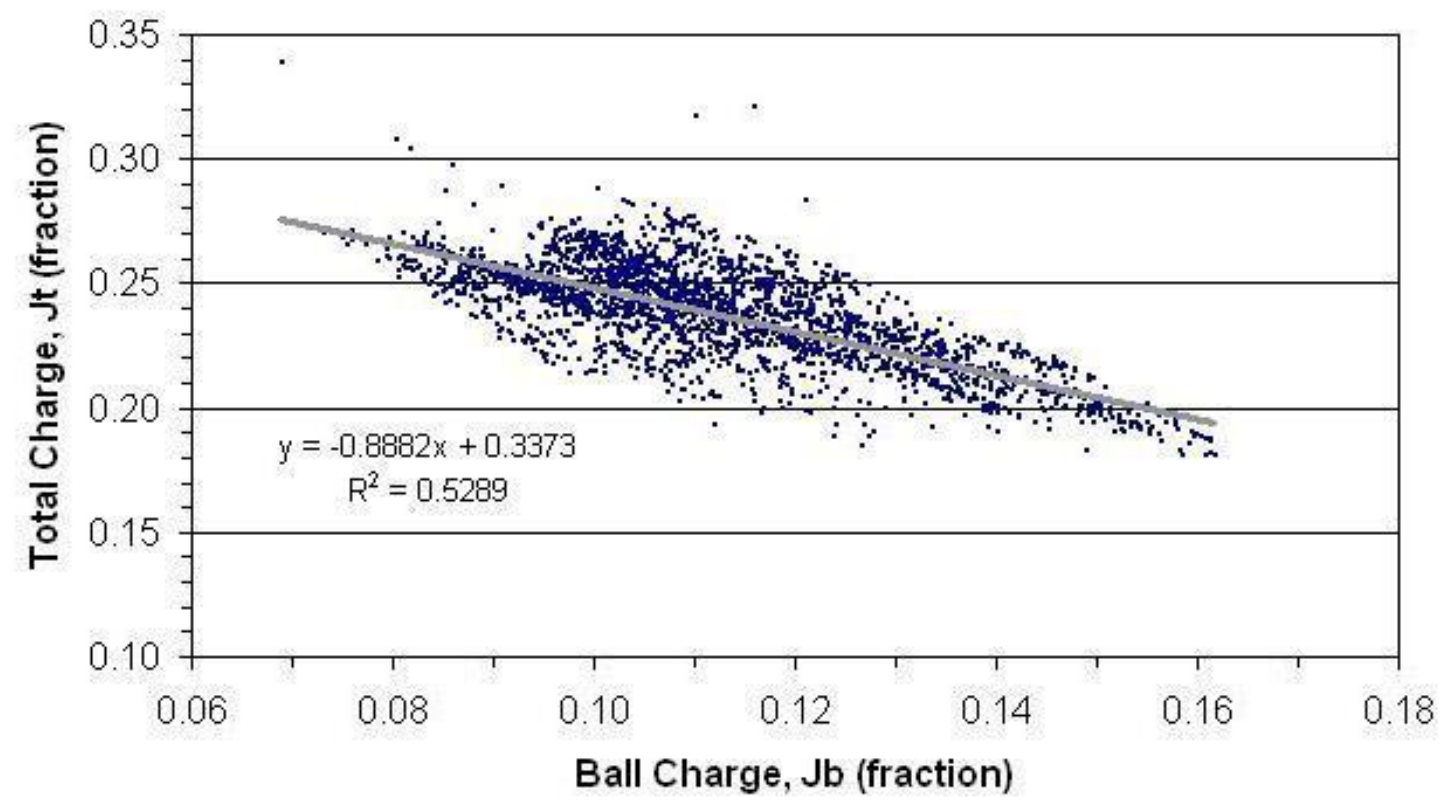

Fig.12 Total charge $\left(J_{t}\right)$ versus ball charge $\left(J_{b}\right)$ plot showing a negative, proportionality. Line of -0.9 slope has moderate variance. Visually, the data forms several steeper striations (slope $c a$. -2).

Although beyond the scope of this research, it could be hypothesised that the apparent bands correspond to different ore hardness levels. This theory could be investigated thoroughly in further research. However, the investigation of the model characteristics here reinforces this argument. The model characteristics and sensitivities were investigated by ramping the model inputs up and down ten percent, one at a time, as described above. Stimulating the powerdraw and weight inputs this way, results in contours for constant weight and powerrdraw, respectively, on the total charge versus ball charge plot, as shown in Figure 13. Contours similar to this were first presented in an earlier paper (Apelt et al. 2001a), except the axes have been swapped here to better reflect the stronger functional dependence on the ball charge estimate, $J_{b}$. 


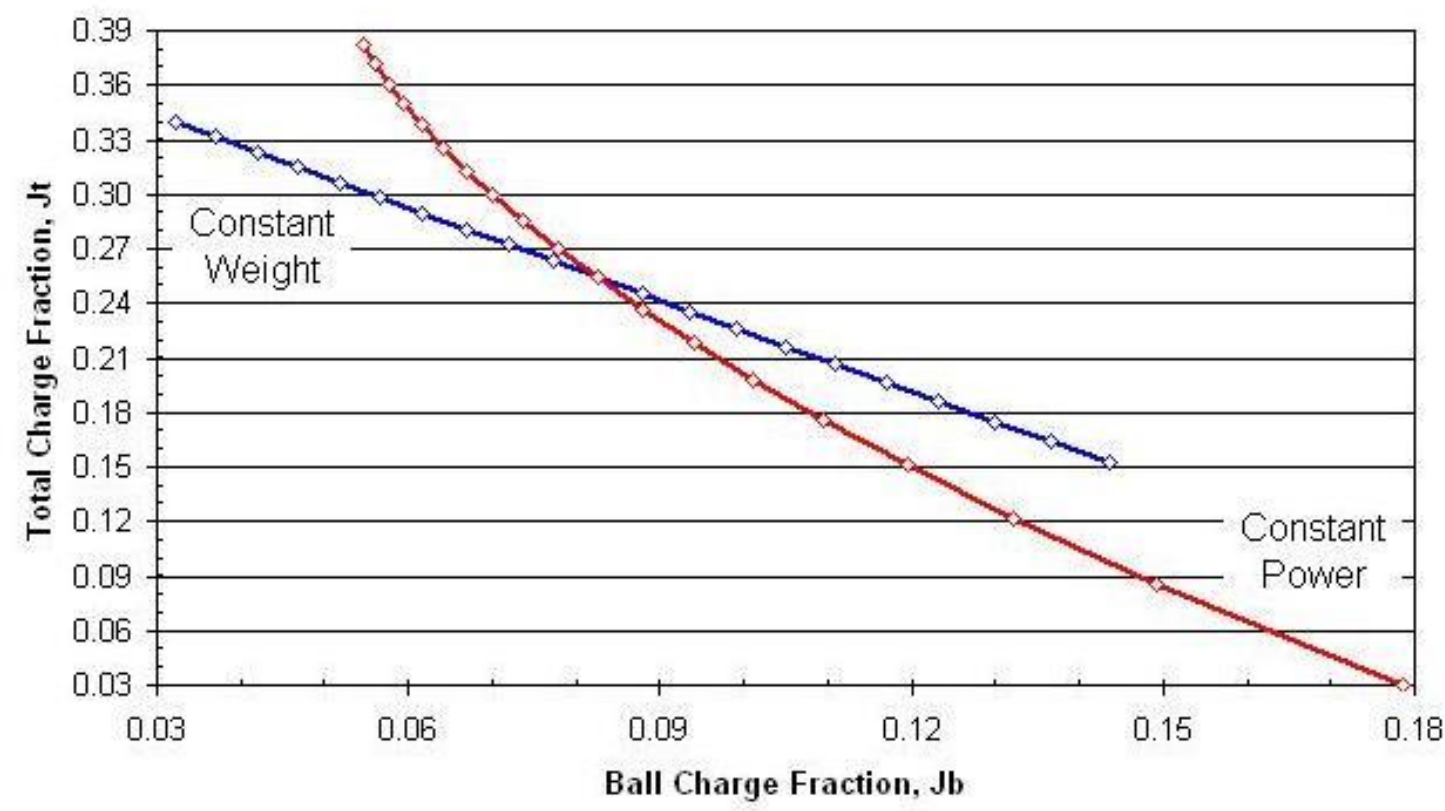

Fig.13 Powerdraw and weight contours (mill powerdraw and weight ramped up and down 10\%) for reference point 14/10/97 11:47 a.m.: $2422 \mathrm{~kW}, 172 \mathrm{t}$

The contours in Figure 13 centre around one nominal operating point with a powerdraw of $2422 \mathrm{~kW}$ and mill weight of $172 \mathrm{t}$. Four other reference operating points were selected arbitrarily from the plant data to encompass high and low mill powerdraw and mill weight. From each of these reference points, the mill powerdraw and weight were ramped up and down $10 \%$ to obtain powerdraw contours and weight contours in the total charge $\left(J_{t}\right)$ - ball charge $\left(J_{b}\right)$ space. Further details about the reference points may be found elsewhere (Apelt, 2007; Apelt and Thornhill, In Press). The contours for constant weight are isolated and shown in Figure 14, with the direction of increasing weight indicated. The contours of constant powerdraw are isolated and shown in Figure 15, with the direction of increasing powerdraw indicated.

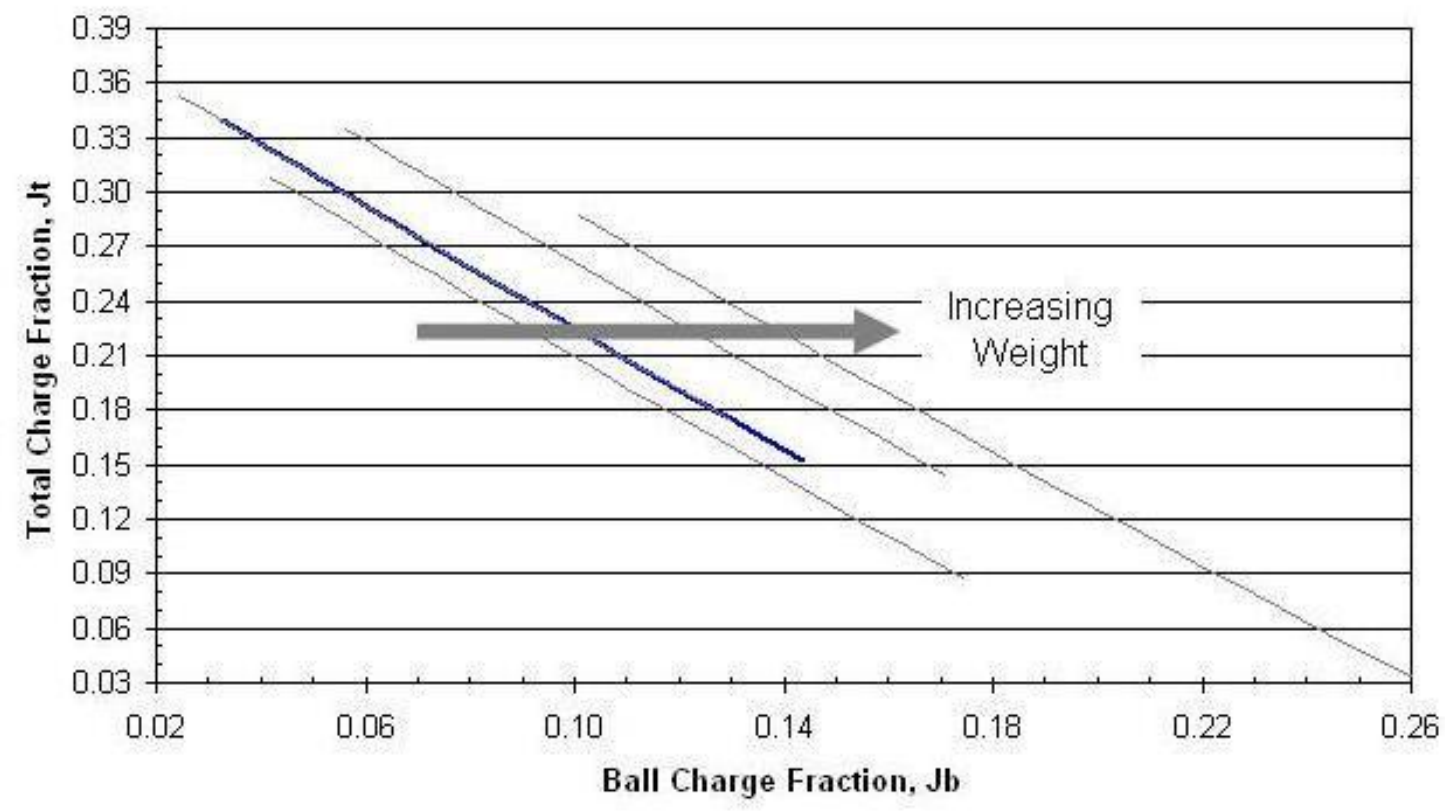


Fig.14 Weight contours (mill powerdraw ramped up and down 10\%). Mill weight increasing left to right.

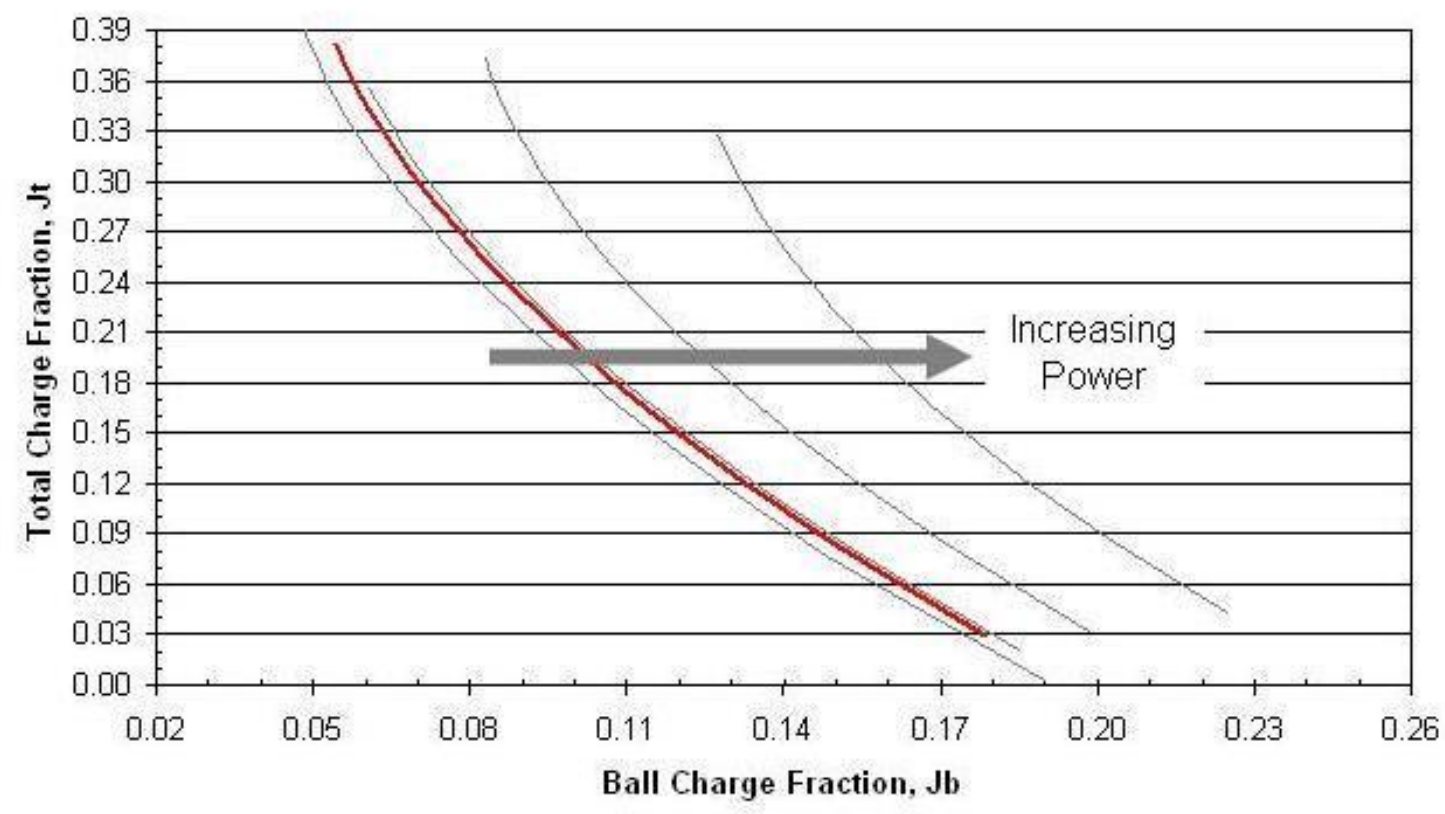

Fig.15 Powerdraw contours (mill weight ramped up and down 10\%). Mill powerdraw increasing left to right.

Comparing the weight contours, Figure 14, and the total charge versus ball charge estmates from plant data, Figure 12, one notes the similarity between the slopes of the contours and the striations. The contours are generated from an encompassing range of operating points, conceivably different due to the prevailing ore hardness.

Noting now the slopes of the contours. The The weight contours, Figure 14, appear linear, whilst, the powerdraw contours, Figure 15, are non-linear. The essential nature of the contours were explored using the symbolic manipulation capabilities of MATLAB. The mill weight residual, Equation (14), and powerdraw residual, Equation (13), were reduced to functions of only ball charge $\left(J_{b}\right)$ and total charge $\left(J_{t}\right)$.

The weight contours were found to be linear as expected. The proportionality constant is between -1.7 and -1.6. This slope is consistent with the slope proposed for striations in Figure 12. As suggested, the different bands could correspond in some way to the weight contours. As such, the contours could, therefore, correspond to different ore hardness levels. Further investigation of this hypothesis could be the focus of future work.

For the powerdraw contours, the total charge estimate, $J_{t}$, was found to proportional to a detailed polynomial in ball charge, $J_{b}$. The polynomial included exponentials of ball charge $\left(e^{J b}\right)$ and sine functions of ball charge and their exponential $\left(\sin e\left(J_{b}\right)\right.$ and sine $\left(e^{J b}\right)$, respectively. Qualitatively, for the powerdraw contours, the total charge estimate, $J_{t}$, was found to be approximately proportional to $J_{b}^{-1.5}$, with a proportionality constant of $1 / 200$.

The uncertainty in the total $\left(J_{t}\right)$ and ball charge $\left(J_{b}\right)$ estimates was previously explored (Apelt et al., 2001a) in an analysis that utilised the application of the general formular for error propagation and the Differentiation of Composite Function rule to the powerdraw and weight residuals, see Equations (13) and (14) above.

The general formula for error propagation (Taylor, 1982) may be applied to the to the mill powerdraw and 
weight residuals to estimate the uncertainty in the charge estimates as follows:

$$
\delta J_{k, i}=\sqrt{\sum_{j=1}^{N}\left(\frac{\partial J_{k, i}}{\partial \theta_{j}} \delta \theta_{j}\right)^{2}}
$$

where $\delta J_{k}$ is the uncertainty in charge estimate $J_{k}$, obtained when using residual $i, \delta \theta_{j}$ is the uncertainty in the $j$ th parameter in the residual, $\partial J_{k} / \partial \theta_{j}$ is the sensitivity of charge estimate $J_{k}$ to parameter $\theta_{j}$, subscript $k$ may be $b$ for ball or $t$ for total charge estimate and $N$ is the number of parameters.

The residuals are functions of the charge estimates. Hence, the sensitivity of the mill charge estimates to errors in the parameters, $\partial J_{k} / \partial \theta_{j}$, is determined by the application of the Differentiation of Composite Function rule or implicit differentiation (see Perry et al., 1984), which can be written as follows:

Given an implicit model equation $F\left(J_{t}, J_{b}, \theta\right)=0$, then for $\partial F / \partial J \neq 0$ :

$$
\frac{\partial J}{\partial \theta}=-\frac{\partial F / \partial \theta}{\partial F / \partial J}
$$

Substituting Eq (29) into both the ball charge and total charge estimate versions of Eq (28) and dividing the results yields:

$$
\frac{\delta J_{t, i}}{\delta J_{b, i}}=\frac{\partial J_{t, i}}{\partial J_{b, i}}
$$

The left-hand side of Equation (30) represents the relative uncertainty in the total charge estimate $\left(J_{t}\right)$ with respect to the uncertainty in the ball charge $\left(J_{b}\right)$. The right-hand side of Equation (30) represents the slope of the contour of residual $i$. Therefore, assessment of the slope of the contours yields a measure of the relative uncertainties in the total and ball charge estimates is possible.

This finding may be applied to the contours in Figure 13. For the weight contour, the uncertainty in the total charge estimate is approximately twice the uncertainty in the ball charge estimate (between 1.6 and 1.7). From the qualitative assessment of the relationship between total and ball charge estimates associated with the powerdraw contour above, the slope of the contour is approximately proportional to $J_{b}{ }^{-2.5}$., with a proportionality constant of $3 / 400$. Therefore, the uncertainty in the total charge estimate increases, relative to the ball charge estimate uncertainty, as the ball charge estimate decreases. Incorporating the shape of the contour, this means that the uncertainty in the total charge estimate $\left(J_{t}\right)$ increases with respect to the the uncertainty in the ball charge estimate $\left(J_{b}\right)$ the higher the total charge is (increased rock charge) compared to the the ball charge.

For a low ball charge fraction estimate, $J_{b}$ of 0.08 , the relative uncertainty of the total charge fraction estimate $\left(J_{t}\right)$ is approximately four (4) times larger. For a high ball charge fraction estimate of 0.18 , the relative uncertainty of the total charge fraction estimate is approximately half $(0.5)$ as large. Therefore, the relative uncertainty is eight $(8=4 / 0.5)$ times higher for the low ball charge estimate conditions. The uncertainties in the estimates are approximately equal for ball charge fraction estimates around 0.14. Further research could include a more formal model fitting of the approximation of the contour, which would improve the estimate of the relative uncertainties in the estimates.

\section{CONCLUSIONS AND RECOMMENDATIONS}


A summary of the development of the inferential measurement models of SAG mill discharge and feed streams and mill rock and ball charge levels reiterates the models detailed earlier in this series of papers.

The inferential measurement models have been tested on plant data. The mill charge fraction (total, ball and rock) estimates were found to contain a significant level of error. However, considering that model fitting parameters are adjustable and that the models trended sensibly, the models were considered valuable with potential for use in SAG mill charge control. Other model limitations were highlighted when unusual process conditions came into effect. Further research is required to further investigate the model limitations and whether there is potential for process diagnosis purposes.

Model sensitivity was further investigated by the artificial stimulation of the key model inputs. The powerdraw and mill weight measurements strongly affect the total, ball and rock charge estimates. The oversize crusher feedrate and mill weight measurements strongly affect the feedsize estimate. Movingaverage filtering of the mill weight and powerdraw measurements is considered a valid strategy to reduce undue model sensitivity to these measurements.

The trending characteristic of the feed size $F_{80}$ estimate was considered of importance and of value to a potential SAG mill charge control strategy. The calculation sequence in the feedsize $F_{80}$ estimate introduces error to the estimate, which was strongly affected by the breakage rates calculation in the mill. Further research could investigate other formulations for estimating the breakage rates that eliminate this sensitivity whilst still capturing the critical features of the breakage rate curve. A moving-average filter on the mill powerdraw and weight signals to reduce the impact of measurement and process noise is also suggested.

Total and ball charge estimate contours for the mill powerdraw and weight measurements were presented for a number of different operating conditions. The slope of the contours was discussed in terms of relative uncertainties in the total and ball charge estimates.

For the weight contour (varying powerdraw) estimates: the total charge estimate ( $\mathrm{Jt}$ ) has been found to be directly proportional to the ball charge estimate $\left(J_{b}\right)$, and, the uncertainty in the total charge estimate $\left(J_{t}\right)$ remains constant with respect to the uncertainty in the ball charge estimate $\left(J_{b}\right)$. The total charge estimate uncertainty being 1.6 to 1.7 times that of the ball charge estimate.

For the mill powerdraw contour (varying weight) estimates: the total charge estimate $\left(J_{t}\right)$ has been found to be approximately proportional to the inverse of the ball charge estimate to the power of $1.5\left(J_{b}^{-1.5}\right)$, and, the uncertainty in the total charge estimate $\left(J_{t}\right)$ varies with respect to the uncertainty in the ball charge estimate $\left(J_{b}\right)$, approximately proportionally to the ball charge estimate to the power minus $2.5\left(J_{b}{ }^{-2.5}\right)$. The total charge estimate uncertainty is relatively high when the ball charge is low and low when the ball charge is high. Further research could include a more formal model fitting of the approximation of the contour, to improve the estimate of the relative uncertainties in the estimates.

\section{NOTE}

Since the first paper (Apelt et al., 2001a) and investigative report (Romagnoli et al., 1997), the process control team at Northparkes Mines have upgraded the PLC controllers in the grinding circuit. The increased capabilities allowed the site to commission the implementation of mill load constraint-control (Thornton et al., 2005). The control strategy employs a pair of microphones for the audio-indication of charge toe position, manipulating feedrate to control charge level subject to an upper constraint on mill powerdraw. The SAG mill control system has a high degree of operator acceptance (95\% utilisation) and can deal with "a wide range of plant disturbances and keep the mill operating at optimal load." 


\section{ACKNOWLEDGEMENTS}

Acknowledgements go to Northparkes Mines for their assistance with and permission to publish circuit information, the Centre for Process Systems Engineering for significant hosting and the University of Sydney for providing Australian Postgraduate Award funding for this research.

\section{REFERENCES}

Apelt, T. A. (1998). Dynamic environment for comminution circuit control, simulation and training. Technical report. Dept of Chemical Engineering. University of Sydney NSW Australia. ME(Research) to PhD Upgrade Report.

Apelt, T.A. (2007). Inferential Measurement Models for Semi-autogenous Grinding Mills. PhD thesis. Department of Chemical Engineering, University of Sydney. See http://www.geocities.com/thomasapelt.

Apelt, T.A., S.P. Asprey and N.F Thornhill (2001a). Inferential measurement of SAG mill parameters. Minerals Engineering 14(6), 575 - 591.

Apelt, T.A., S.P. Asprey and N.F. Thornhill (2001b). SAG mill discharge measurement model for combined state and parameter estimation. In: SAG 2001. Vol. IV. UBC. Vancouver, B.C., Canada. pp. 138-149. Third international conference on: Autogenous and Semiautogenous Grinding Technology.

Apelt, T.A., S.P. Asprey and N.F Thornhill (2002a). Inferential measurement of SAG mill parameters II: state estimation. Minerals Engineering 15(12), 1043 - 1053.

Apelt, T.A., S.P. Asprey and N.F Thornhill (2002b). Inferential measurement of SAG mill parameters III: inferential models. Minerals Engineering 15(12), 1055 - 1071.

Apelt, T.A. and N.F Thornhill (In Press). Inferential measurement of SAG mill parameters V: MPC simulation. Minerals Engineering.

Fuenzalida, R., E. Cubillos and J. Sepulveda (1996). Plant Experiences on Expert Supervisor Control of Semiautogenous Grinding Circuits. In: SAG 1996. Vol. 2. UBC. Vancouver, B.C., Canada. pp. 642656. Second international conference on: Autogenous and Semiautogenous Grinding Technology.

JKTech (1994). JK SimMet steady state mineral processing simulator: User Manual Version 4 (including the Variable Rates SAG Model - Appendix A11, Version 4.3 1997). JKTech - JKMRC Commercial Division. Julius Kruttschnitt Mineral Reseach Centre, University of Queensland, Australia.

Morrell, S. (1994). Powerdraw Draw of Grinding Mills - Its Measurement and Prediction. In: Fifth Mill Operators Conference. Olympic Dam, Australia. pp. 109-114.

Morrell, S. and R.D. Morrison (1996). AG and SAG Mill Circuit Selection and Design by Simulation. In: SAG 1996. UBC. Vancouver, B.C., Canada. pp. 769-790. Second international conference on: Autogenous and Semiautogenous Grinding Technology.

Morrell, S., W. Valery, G. Banini and S. Latchireddi (2001). Developments in AG/SAG Mill Modelling. In: SAG 2001. Vol. IV. UBC. Vancouver, B.C., Canada. pp. 71 84. Third international conference on: Autogenous and Semiautogenous Grinding Technology.

Napier-Munn, T. J., S. Morrell, R. D. Morrison and T. Kojovic (1996). Mineral Comminution Circuits Their Operation and Operation. Julius Kruttschnitt Mineral Research Centre, Australia.

Perry, T.H., Green, D.W. and Maloney, J.O., Eds.) (1984). Perry's Chemical Engineers' Handbbok. 6th ed.. McGraw-Hill.

Romagnoli, J. A., O. Galan and T. A. Apelt (1997). Preliminary Study of SAG Mill Control at Northparkes Mines. Technical report. ICI Laboratory for Process Systems Engineering. Dept of Chemical Eng, University of Sydney NSW Australia.

Taylor, J.R (1982). An Introduction to Error Analysis: The Study of Uncertainties in Physical Measurements. University Science Books.

Thornton, A.J., T. Pethybridge, T. Rivett and R. Dunn (2005). SAG Mill Control at Northparkes Mines (Not So Hard After All). www.mipac.com.au.

Valery Jnr, Walter and Steve. Morrell (1995). The Development of a Dyamic Model for Autogenous and Semi-Autogenous Grinding. In: Minerals Engineering Conference, St. Ives, England.

Whiten, W.J. (1974). A Matrix Theory of Comminution Machines. Chemical ENgineering Science 29, 589-599. 